\title{
Mesoporous Silica Nanoparticles Trigger Liver and Kidney Injury and Fibrosis Via Altering TLR4/NF- $k B$, JAK2/STAT3 and Nrf2/HO-1 Signaling in Rats
}

\author{
Ayman M. Mahmoud ${ }^{1, *(D)}$, Ekram M. Desouky ${ }^{2}$, Walaa G. Hozayen ${ }^{2}$, , May Bin-Jumah $^{3}$, \\ El-Shaymaa El-Nahass ${ }^{4}$, Hanan A. Soliman ${ }^{2}$ and Ahmed A. Farghali ${ }^{5}$ \\ 1 Physiology Division, Zoology Department, Faculty of Science, Beni-Suef University, Beni-Suef 62514, Egypt \\ 2 Biochemistry Department, Faculty of Science, Beni-Suef University, Beni-Suef 62514, Egypt; \\ ekram_md@yahoo.com (E.M.D.); walaahozayen@hotmail.com (W.G.H.); \\ hanan_abdelhameid@yahoo.com (H.A.S.) \\ 3 Department of Biology, College of Science, Princess Nourah bint Abdulrahman University, Riyadh 84428, \\ Saudi Arabia; may_binjumah@outlook.com \\ 4 Department of Pathology, Faculty of Veterinary Medicine, Beni-Suef University, Beni-Suef 62514, Egypt; \\ shima_k81@yahoo.com \\ 5 Materials Science and Nanotechnology Department, Faculty of Postgraduate Studies for Advanced \\ Sciences (PSAS), Beni-Suef University, Beni-Suef 62514, Egypt; ahmedfarghali74@yahoo.com \\ * Correspondence: ayman.mahmoud@science.bsu.edu.eg
}

Received: 16 August 2019; Accepted: 17 September 2019; Published: 25 September 2019

\begin{abstract}
Mesoporous silica nanoparticles (MSNs) represent a promising inorganic platform for multiple biomedical applications. Previous studies have reported MSNs-induced hepatic and renal toxicity; however, the toxic mechanism remains unclear. This study aimed to investigate MSNs-induced hepatic and nephrotoxicity and test the hypothesis that altered TLR4/MyD88/NF-KB, JAK2/STAT3, and Nrf2/ARE/HO-1 signaling pathways mediate oxidative stress, inflammation, and fibrosis induced by MSNs. Rats were administered 25, 50, 100, and $200 \mathrm{mg} / \mathrm{kg}$ MSNs for 30 days, and samples were collected for analyses. MSNs induced functional and histologic alterations, increased the levels of reactive oxygen species (ROS), lipid peroxidation and nitric oxide, suppressed antioxidants, and Nrf2/HO-1 signaling in the liver and kidney of rats. MSNs up-regulated the expression of liver and kidney TLR4, MyD88, NF-KB p65, and caspase-3 and increased serum pro-inflammatory cytokines. In addition, MSNs activated the JAK2/STAT3 signaling pathway, down-regulated peroxisome proliferator activated receptor gamma (PPAR $\gamma$ ), and promoted fibrosis evidenced by the increased collagen expression and deposition. In conclusion, this study conferred novel information on the role of ROS and deregulated TLR4/MyD88/NF-kB, JAK2/STAT3, PPAR $\gamma$, and Nrf2/ARE/HO-1 signaling pathways in MSNs hepatic and nephrotoxicity. These findings provide experimental evidence for further studies employing genetic and pharmacological strategies to evaluate the safety of MSNs for their use in nanomedicine.
\end{abstract}

Keywords: mesoporous silica; Nrf2; oxidative stress; fibrosis; NF- $\kappa B$

\section{Introduction}

Nanotechnology has emerged as a novel approach to the development and application of nanostructured materials in both industry and medicine [1]. Silica nanoparticles (SiNPs) possess distinct physicochemical characteristics and are now widely used in different fields [2]. The massive industrial production and global commercialization have raised the risk of human exposure to SiNPs [3]. In this context, the food additive E551 is a silicon dioxide in the nano-size range [4], and 
hence, the general population is exposed to it [3]. Recently, the European Food Safety Authority panel recommended a reevaluation of E551 as a food additive [5]. In addition, the use of NPs in disease diagnosis and treatment can intentionally expose humans to SiNPs [6].

Mesoporous SiNPs (MSNs) represent a promising inorganic platform for multiple applications. Given their unique characteristics, including large pore volume, high surface area, inherent biodegradability, and chemical stability, MSNs have been employed in a variety of fields [7]. MSNs have recently attracted substantial attention for use in biomedical applications, such as bioimaging, targeted drug delivery, biosensing, and others [8,9]. In addition to their unique properties, MSNs can protect their cargos from premature release and degradation [10]. Therefore, MSNs represent a promising vehicle for drug delivery. However, their toxic effects might hinder their applications in biology, medicine, and industry. The lack of data on the toxicological profile of MSNs is a major challenge to the use of MSNs in drug delivery [11]. Thus, studies are needed to evaluate the potentially toxic effects of MSNs and to explore the underlying mechanisms, particularly for improving the performance of nanomedicine.

The growing global exposure to SiNPs raised a concern regarding their impact on human safety and health [3]. In this context, several in vitro and in vivo studies have been conducted to assess the toxic potential of SiNPs (reviewed in $[3,12]$ ). In addition, SiNPs have been shown to be as reactive as crystalline silica which is associated with silicosis, emphysema, and lung cancer [13]. Most of the studies have pointed to the major role of reactive oxygen species (ROS) in SiNPs toxicity. In vivo, MSNs induced oxidative stress in rodents as evidenced by increased lipid peroxidation and diminished antioxidants in the heart, lung [14], and liver [15]. ROS can activate nuclear factor-kappaB (NF-kB) and subsequently, the production of inflammatory mediators. Therefore, inflammation may play a substantial role in the toxicity of SiNPs. Accordingly, SiNPs elicited an inflammatory response in macrophages and the kidney of mice $[16,17]$. In addition to oxidative stress and inflammation, recent studies have reported SiNPs-induced hepatic [15] and renal fibrosis [17] in mice. Although these studies pointed to the involvement of transforming growth factor (TGF)- $\beta 1 / \mathrm{Smad} 3$ signaling in mediating SiNPs-induced fibrogenesis, other mechanisms seem to be implicated. Therefore, we explored the potential hepatic toxicity and nephrotoxicity of MSNs with an emphasis on oxidative stress, inflammation, and fibrosis, and the underlying mechanisms. We investigated the dose-dependent effect of MSNs on ROS production and nuclear factor erythroid 2-related factor 2 (Nrf2) /heme oxygenase 1 (HO-1), a signaling pathway that mainly regulates the expression of antioxidant enzymes and inhibits oxidative stress and inflammation [18]. To explore the mechanism underlying MSNs-induced inflammation and fibrosis, we scrutinized the possible involvement of toll-like receptor 4 (TLR4)/MyD88 and Janus kinase 2/signal transducer and activator of transcription 3 (JAK2/ STAT3) signaling. TLR4 contributes to NF- $\kappa$ B activation, and the release of inflammatory mediators [19] and persistent activation of STAT3 has been implicated in the progression of fibrosis $[20,21]$. Furthermore, our study pointed to the impact of MSNs on the expression of peroxisome proliferator activated receptor gamma (PPAR $\gamma)$, a critical regulator of adipocyte differentiation and glucose homeostasis, that suppresses NF- $\kappa$ B-mediated pro-inflammatory responses [22] and attenuates fibrosis [23,24].

\section{Materials and Methods}

\subsection{Synthesis and Characterization of MSNs}

MSNs were prepared and characterized as previously described (Supplementary material) [14,25].

\subsection{Animals and Treatments}

Eight-week-old male Wistar rats, weighing 140-160 g, were obtained from VACSERA (Giza, Egypt) and housed in standard cages for one week before the start of the experiment. The animals were supplied a standard chow diet and water ad libitum and maintained on a $12 \mathrm{~h}$ light/dark cycle at normal temperature $\left(23 \pm 2{ }^{\circ} \mathrm{C}\right)$ and humidity (50-60\%). The experimental protocol and all animal procedures were approved by the Institutional Animal Ethics Committee of Beni-Suef University (Egypt). 
Thirty rats were divided randomly into five groups $(n=6)$. One group was kept as control and received a single intraperitoneal (ip) injection of $0.9 \%$ saline daily for 30 days. The other groups received different ip doses of MSNs (25,50, 100 and $200 \mathrm{mg} / \mathrm{kg}$ ) daily for 30 days. MSNs were suspended in $0.9 \%$ saline and frequently sonicated to avoid aggregation and sedimentation. During the experiment, mortality and clinical manifestations were reported.

\subsection{Collection and Preparation of Samples}

The animals were fasted overnight and were sacrificed under anesthesia. Blood samples were collected to prepare serum for the assay of liver and kidney function markers, interleukin (IL)-1 $\beta$, IL-6, and tumor necrosis factor (TNF)- $\alpha$. The animals were dissected immediately, and the liver and kidney were excised and washed in cold phosphate-buffered saline (PBS). Samples from the kidney and liver were fixed in $10 \%$ neutral buffered formalin (NBF) or kept at $-80{ }^{\circ} \mathrm{C}$. Other samples were homogenized $(10 \% w / v)$ in cold PBS. After centrifugation of the homogenate, the clear supernatant was collected for analysis.

\subsection{Assay of Liver and Kidney Function Markers and Pro-Inflammatory Cytokines}

Serum levels of alanine aminotransferase (ALT), aspartate aminotransferase (AST), alkaline phosphatase (ALP), bilirubin, albumin, creatinine, and urea were determined using reagent kits supplied by Spinreact (Girona, Spain). IL-1 $\beta$, IL-6, and TNF- $\alpha$ were measured in serum samples using ELISA kits (R\&D Systems, Minneapolis, MN, USA).

\subsection{Assay of Oxidative Stress Markers and Antioxidants}

The level of ROS was determined in the homogenate samples using $2^{\prime}, 7^{\prime}$-dichlorodihydrofluorescein diacetate, as previously described [14,26]. Malondialdehyde (MDA), nitric oxide (NO), reduced glutathione (GSH), superoxide dismutase (SOD), catalase (CAT), and glutathione peroxidase (GPx) were determined using commercially available kits.

\subsection{Gene Expression}

Quantitative reverse transcriptase real-time polymerase chain reaction (qRT-PCR) was used to determine the effect of MSNs on the expression of collagen in the liver and kidney of rats. Briefly, RNA was isolated from the frozen samples using TRIzol (Invitrogen, Waltham, MA, USA) and was quantified using a nanodrop. RNA samples with A260/A280 $\geq 1.8$ were selected. The integrity of RNA samples was confirmed using formaldehyde agarose gel. One $\mu \mathrm{g}$ of RNA was reverse transcribed into cDNA, which was then amplified using SYBR Green and the set of primers listed in Table 1. The obtained amplification data were analyzed using the $2^{-\Delta \Delta \mathrm{Ct}}$ method [27] and normalized to $\beta$-actin.

Table 1. Primers used for qRT-PCR.

\begin{tabular}{ccc}
\hline Gene & Forward Primer Sequence $\left(5^{\prime}-\mathbf{3}^{\prime}\right)$ & Reverse Primer Sequence $\left(\mathbf{5}^{\prime} \mathbf{-} \mathbf{3}^{\prime} \mathbf{)}\right.$ \\
\hline COL1A1 & GTACATCAGCCCAAACCCCA & CAGGATCGGAACCTTCGCTT \\
COL3A1 & AGGGCAGGGAACAACTGATG & GGTCCCACATTGCACAAAGC \\
$\beta$-actin & AGGAGTACGATGAGTCCGGC & CGCAGCTCAGTAACAGTCCG \\
\hline
\end{tabular}

qRT-PCR: quantitative reverse transcriptase real-time polymerase chain reaction.

\subsection{Western Blotting}

The frozen liver and kidney samples were homogenized in radioimmunoprecipitation assay (RIPA) buffer supplemented with proteinase inhibitors. The homogenate was centrifuged at $10000 \mathrm{rpm}$, and the supernatant was collected, and protein concentration was determined using the Bradford protein assay kit (BioBasic, Markham, Canada). Forty $\mu \mathrm{g}$ of protein from each sample was electrophoresed using 10\% sodium dodecyl sulfate-polyacrylamide gel electrophoresis (SDS-PAGE) and transferred 
to nitrocellulose membranes. The membranes were blocked with 5\% skimmed milk in Tris-buffered saline/Tween 20 (TBST) for $1 \mathrm{~h}$ at room temperature (RT). The blocked membranes were probed with primary antibodies against TLR4, MyD88, NF-kB p65, p-JAK2, JAK2, p-STAT3, STAT3, suppressor of cytokine signaling 3 (SOCS3), cleaved caspase-3, PPAR $\gamma, \mathrm{Nrf2}, \mathrm{HO}-1$, and glyceraldehyde-3-phosphate dehydrogenase (GAPDH) (Novus Biologicals, Centennial, CO, USA) overnight at $4{ }^{\circ} \mathrm{C}$. After washing with TBST, the membranes were incubated with secondary antibodies and developed by an enhanced chemiluminescence kit (BIO-RAD, Hercules, CA, USA). The bands were quantified by ImageJ (version $1.32 \mathrm{j}, \mathrm{NIH}, \mathrm{USA})[28]$, normalized to GAPDH and presented as a percent of the control.

\subsection{Histological Examination}

The liver and kidney samples collected on $10 \%$ NBF were fixed for $48 \mathrm{~h}$. The tissues were processed via routine histological procedures, and $5-\mu \mathrm{m}$ sections were cut using a microtome. For examination and scoring the histological alterations, the sections were stained with hematoxylin and eosin (H\&E), whereas Masson's trichrome (MT) staining was used to evaluate hepatic and renal collagen deposition. The MT-positive areas were quantified using ImageJ.

\subsection{Statistical Analysis}

The obtained data were analyzed using GraphPad Prism 7 (GraphPad Software, San Diego, CA, USA) and expressed as mean \pm standard error of the mean (SEM). All statistical comparisons were performed by one-way ANOVA test followed by Tukey's test. The difference was considered significant at $p$-value less than 0.05 .

\section{Results}

\subsection{Characterization of MSNs}

Both the scanning and transmission electron microscopy (SEM and TEM) examination of MSNs revealed spherical, non-aggregated, and well-dispersed particles with uniform size ( $50 \mathrm{~nm})$ and uniformly scattered dendrimeric fibers (Figure 1). In addition, we have recently characterized the prepared MSNs using dynamic light scattering (DLS), zeta potential measurement, thermogravimetric analysis (TGA)/Differential scanning calorimetry (DSC) and X-ray diffraction (XRD) as represented in Supplementary Figure S1 [14].
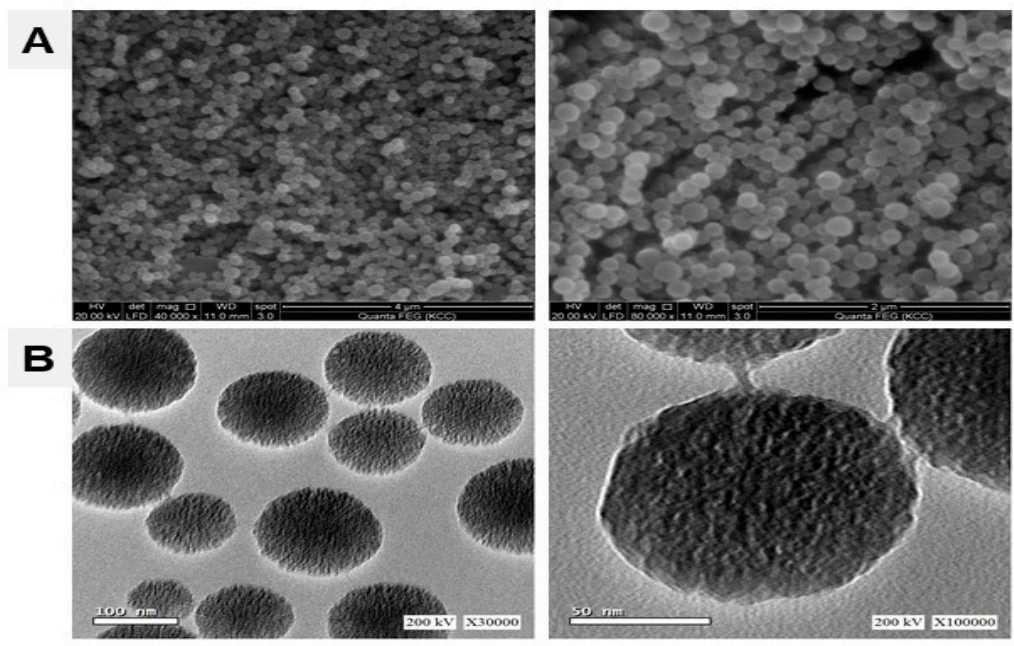

Figure 1. Scanning electron microscopy (SEM) (A) transmission electron microscopy (TEM) (B) of mesoporus silica nanoparticles (MSNs) showing spherical, non-aggregated, and well-dispersed particles with uniform size. 


\subsection{MSNs Induce Hepatic and Nephrotoxicity in Rats}

To evaluate the effect of MSNs on liver and kidney of rats, we measured liver and kidney function markers and performed a histologic examination. Rats received MSNs showed a significant $(p<0.001)$ increase in serum ALT, AST, and ALP when compared with the control group (Table 2). Serum bilirubin was remarkably increased in rats received $25(p<0.05), 50(p<0.05), 100(p<0.05)$ and $200 \mathrm{mg} / \mathrm{kg}$ $(p<0.001)$ MSNs as represented in Table 2. In contrast, serum albumin was decreased in rats received 50 ( $p<0.05), 100(p<0.01)$, and $200 \mathrm{mg} / \mathrm{kg}(p<0.001)$ MSNs, while showed non-significant changes at the lower dose (Table 2). Creatinine and urea were increased in $25(p<0.001 ; p<0.01), 50(p<0.001$; $p<0.01), 100(p<0.001 ; p<0.01)$, and $200 \mathrm{mg} / \mathrm{kg}(p<0.001 ; p<0.001)$ MSNs-administered rats (Table 2).

Table 2. Effect of MSNs on liver and kidney function markers in rats.

\begin{tabular}{|c|c|c|c|c|c|}
\hline & Control & \multicolumn{4}{|c|}{ MSNs } \\
\hline ALT (U/L) & $21.63 \pm 1.71$ & $82.86 \pm 7.45^{* * *}$ & $109.71 \pm 3.19 * * *$ & $111.36 \pm 3.79 * * *$ & $137.07 \pm 4.69 * * *$ \\
\hline AST (U/L) & $47.27 \pm 2.34$ & $153.06 \pm 5.09 * * *$ & $157.20 \pm 13.65^{* * *}$ & $175.19 \pm 9.87^{* * *}$ & $179.00 \pm 4.39^{* * *}$ \\
\hline ALP (U/L) & $166.50 \pm 7.97$ & $305.31 \pm 10.74 * * *$ & $313.09 \pm 8.23^{* * *}$ & $589.14 \pm 27.16^{* * *}$ & $735.93 \pm 25.09 * * *$ \\
\hline Bilirubin (mg/dl) & $0.52 \pm 0.07$ & $1.86 \pm 0.17 *$ & $1.83 \pm 0.26 *$ & $1.82 \pm 0.21 *$ & $2.95 \pm 0.42 * * *$ \\
\hline Urea $(\mathrm{mg} / \mathrm{dl})$ & $27.51 \pm 1.72$ & $55.87 \pm 4.65^{* *}$ & $60.07 \pm 2.86 * *$ & $58.46 \pm 3.06^{* *}$ & $81.85 \pm 5.99 * * *$ \\
\hline
\end{tabular}

Data are mean \pm standard error of the mean (SEM) $(n=6) .{ }^{*} p<0.05,{ }^{* *} p<0.01$, and ${ }^{* * *} p<0.001$ vs. control.

The hepatic and nephrotoxic effects of MSNs were confirmed by the histopathological findings. H\&E-stained sections in the liver (Figure 1; Left panel) of control group revealed the normal structure of the hepatic lobules, hepatocytes, and sinusoids (Figure 2A-B). The liver of animals received $25 \mathrm{mg} / \mathrm{kg}$ (Figure 2C-D) and $50 \mathrm{mg} / \mathrm{kg}$ (Figure 2E-F) MSNs showed multiple histological alterations, including degenerative changes, necrosis, leukocyte infiltration in the portal area, fatty changes, congestion and Kupffer cells (KCs) proliferation. In addition to these alterations, rats received $100 \mathrm{mg} / \mathrm{kg}$ and 200 $\mathrm{mg} / \mathrm{kg}$ MSNs exhibited granulomatous reactions as showed in Figure 2G-J, respectively, and Table 3. 


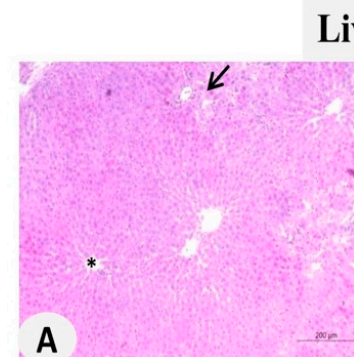

Liver
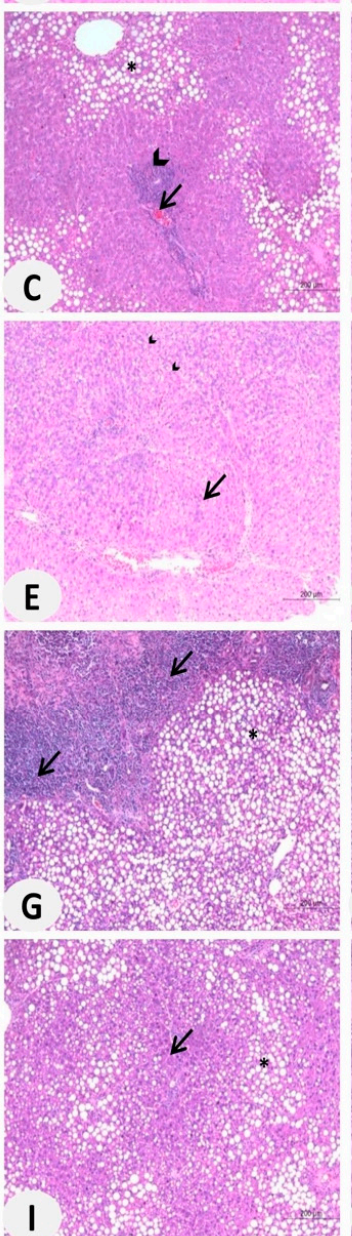
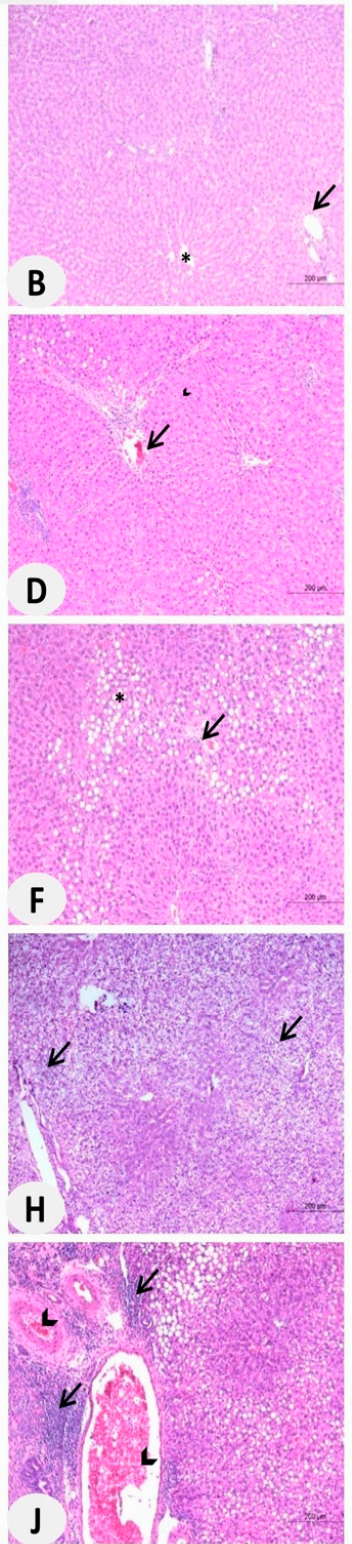
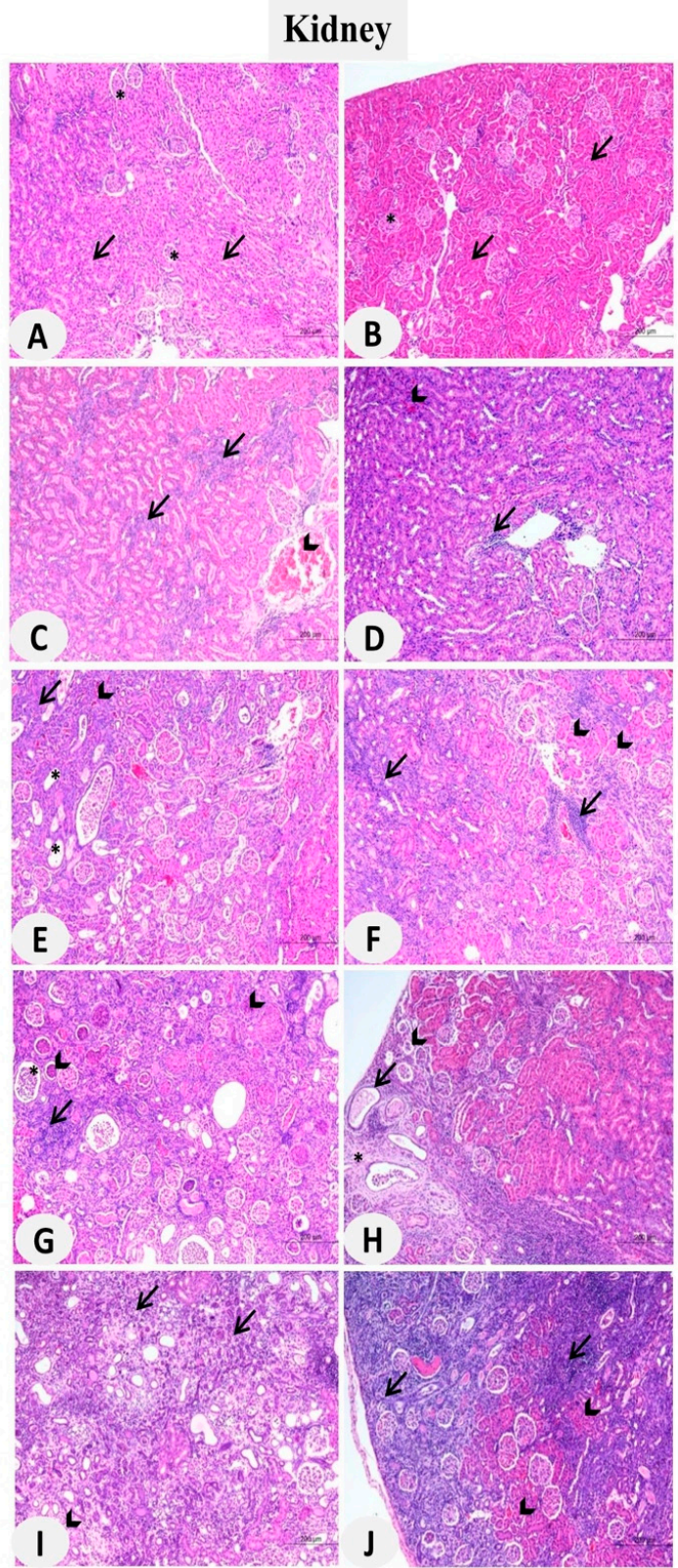

Figure 2. MSNs-induced histological alteration in the liver and kidney of rats. (Left panel) Photomicrographs of liver sections of $(\mathbf{A}, \mathbf{B})$ control group showing normal hepatic lobule, central veins ${ }^{*}$ ), and portal area (arrows), (C,D) rats received $25 \mathrm{mg} / \mathrm{kg}$ MSNs showing moderate fatty changes of hepatocytes $\left({ }^{*}\right)$, mild leukocyte infiltration in portal areas (arrow head), congestion (arrow) (C), degenerative changes, proliferation of Kupffer cells (KCs) (arrow heads) and leukocyte infiltration in the portal area (arrow) (D), (E,F) rats received $50 \mathrm{mg} / \mathrm{kg}$ MSNs showing degenerative changes of hepatocytes (arrows), proliferation of KCs (arrow heads) (E), fatty changes of hepatocytes $\left(^{*}\right)$, leukocyte infiltration and congestion (arrow) (F), (G,H) rats received $100 \mathrm{mg} / \mathrm{kg}$ MSNs showing fatty changes $\left({ }^{*}\right)$, leukocyte infiltration (arrows) (G), and vacuolar degeneration (arrows) $(\mathbf{G})$, and (I,J) rats received $200 \mathrm{mg} / \mathrm{kg}$ MSNs showing fatty changes $\left(^{*}\right)$, necrosis (arrows) (I), leukocyte infiltration (arrows) and congestion (arrow heads) (J). (Right panel) Photomicrographs of kidney of $(\mathbf{A}, \mathbf{B})$ control group showing normal glomeruli $\left(^{*}\right)$ and renal tubules (arrow head), (C,D) rats received $25 \mathrm{mg} / \mathrm{kg}$ MSNs showing interstitial inflammatory cell aggregates (arrows), congestion (arrow head) (C), perivascular inflammatory cell 
aggregates (arrows) and congestion (arrow head) (D), (E,F) rats received $50 \mathrm{mg} / \mathrm{kg}$ MSNs showing inflammatory cell reaction (arrows), dilation of some renal tubules $\left({ }^{*}\right)$, congestion (arrow head) (E), inflammatory cell reactions (arrows) and necrosis (arrow head) $(\mathbf{F}),(\mathbf{G}, \mathbf{H})$ rats received $100 \mathrm{mg} / \mathrm{kg}$ MSNs showing inflammatory cell aggregates (arrows), dilatation of Bowman's space ${ }^{*}$ ), glomerular atrophy (arrow heads) $(\mathrm{G})$, proliferation of fibrous connective tissues $\left(^{*}\right)$, dilation of renal tubules (arrow), and necrosis (H) and (I,J) rats received $200 \mathrm{mg} / \mathrm{kg}$ MSNs showing necrotic changes (arrows), proliferation of interstitial fibrous connective tissues (arrow head) (I), lymphocytic interstitial nephritis (arrows) and coagulative necrosis (arrow heads) (J). (hematoxylin-eosin, H\&E, X100).

Table 3. Histopathological alterations in liver and kidney of MSNs-induced rats.

\begin{tabular}{|c|c|c|c|c|c|}
\hline & \multirow{2}{*}{ Control } & \multicolumn{4}{|c|}{ MSNs (mg/kg) } \\
\hline & & 25 & 50 & 100 & 200 \\
\hline \multicolumn{6}{|c|}{ Liver } \\
\hline Degenerative changes & - & ++ & ++ & +++ & +++ \\
\hline Necrosis & - & ++ & ++ & +++ & +++ \\
\hline Leukocyte infiltration & - & - & - & - & - \\
\hline Hepatic parenchyma & - & - & - & - & - \\
\hline Portal area & - & + & + & ++ & ++ \\
\hline Congestion & - & + & ++ & ++ & ++ \\
\hline Granulomatous reactions & - & - & - & + & + \\
\hline Fatty changes & - & + & + & + & + \\
\hline Kupffer cell activation & - & + & ++ & ++ & +++ \\
\hline \multicolumn{6}{|c|}{ Kidney } \\
\hline Tubular degeneration & - & + & ++ & ++ & +++ \\
\hline Tubular necrosis & - & - & ++ & ++ & +++ \\
\hline Glomerulonephritis & - & + & + & ++ & +++ \\
\hline Glomerular atrophy & - & + & - & + & +++ \\
\hline Glomerular hypercellularity & - & + & ++ & ++ & ++ \\
\hline Bowman's capsule dilation & - & - & - & - & + \\
\hline Leukocyte infiltration & - & ++ & +++ & +++ & +++ \\
\hline Chronic nephritis & - & + & ++ & ++ & +++ \\
\hline Others & - & - & Cast & $\begin{array}{l}\text { Cast, edema, } \\
\text { tubular } \\
\text { dilation, } \\
\text { cystic dilation }\end{array}$ & $\begin{array}{l}\text { Cystic dilation, } \\
\text { cast }\end{array}$ \\
\hline
\end{tabular}

Normal histological architecture of the capsule, cortex, medulla, renal tubules, and glomeruli was observed in the kidney sections of control rats (Figure 3A,B, Right panel). However, rats received the lower dose of MSNs showed tubular degeneration, glomerulonephritis, glomerular hypercellularity, leukocyte infiltration and chronic nephritis (Figure 3C,D). In addition to these manifestations, tubular necrosis was noticed in rats received $50 \mathrm{mg} / \mathrm{kg}$ MSNs (Figure 3E,F), whereas the 100 (Figure 3G,H) and $200 \mathrm{mg} / \mathrm{kg}$ (Figure 3I,J) MSNs induced glomerular atrophy, tubular dilatations, casts, cystic dilatation, and edema. Dilatation of Bowman's capsule was observed in the kidney of rats administered with 200 $\mathrm{mg} / \mathrm{kg}$ MSNs (Table 3). 
A

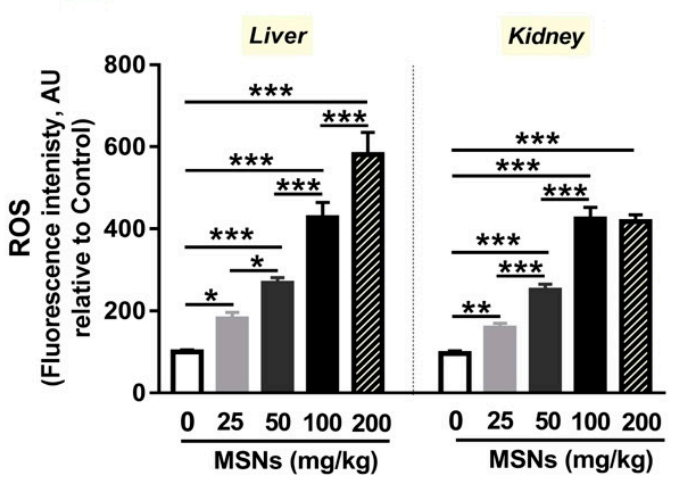

C

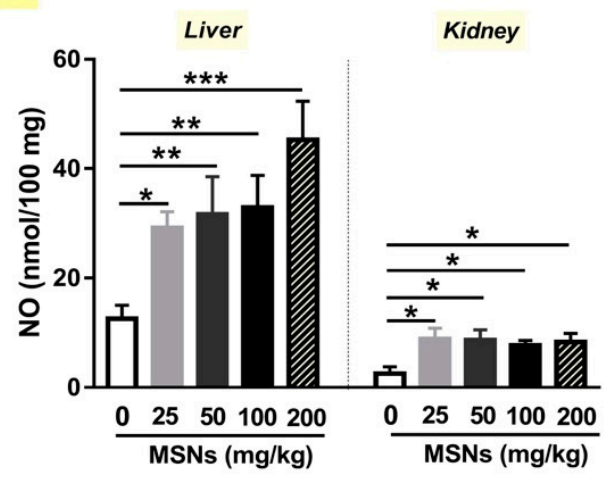

E

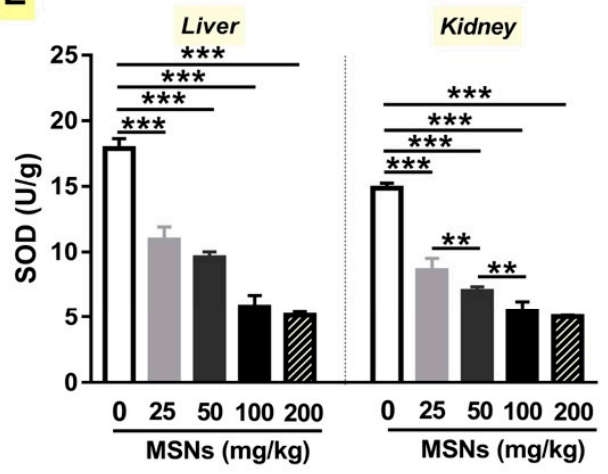

B

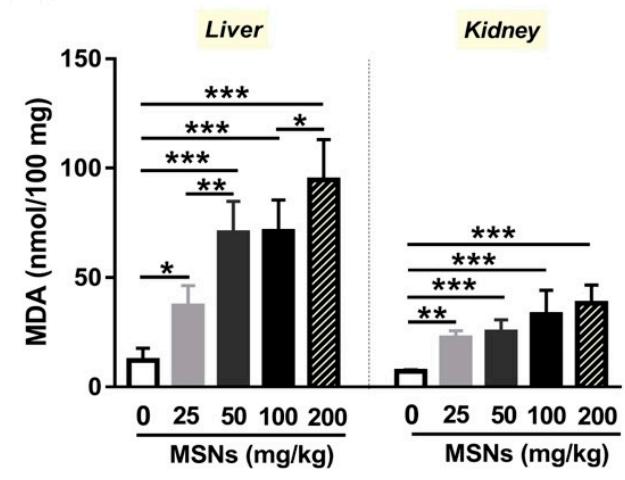

D

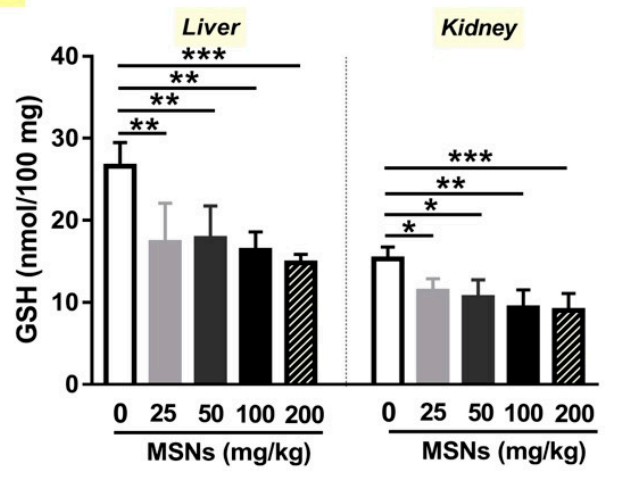

$\mathbf{F}$

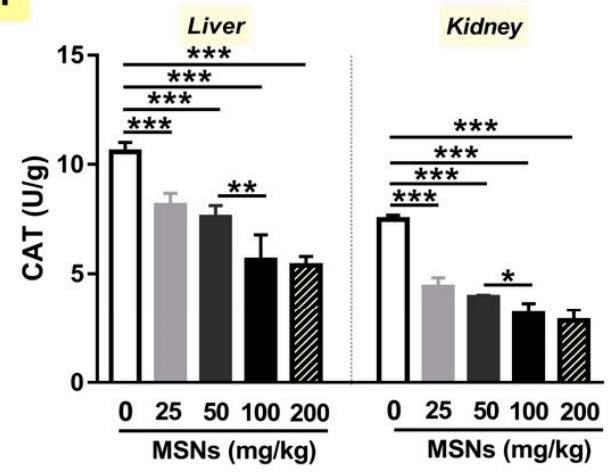

G

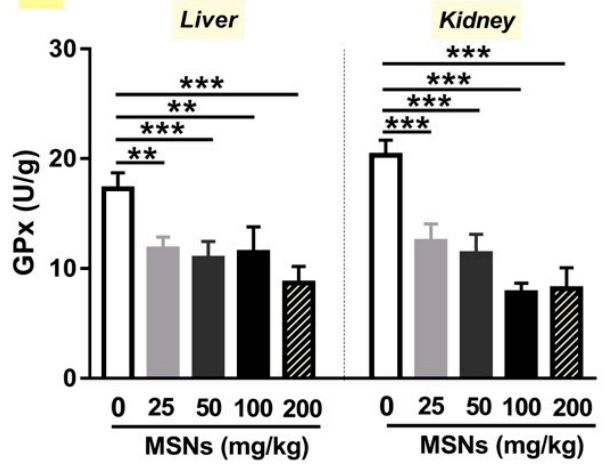

Figure 3. MSNs provoke reactive oxygen species (ROS) production and oxidative stress in liver and kidney of rats. MSNs increased ROS (A), malondialdehyde (MDA) (B) and nitric oxide (NO) (C), and diminished reduced glutathione (GSH) (D), superoxide dismutase (SOD) (E), catalase (CAT), (F) and glutathione peroxidase (GPx) (G). Data are Mean $\pm \operatorname{SEM}(n=6) .{ }^{*} p<0.05,{ }^{* *} p<0.01$, and ${ }^{* * *} p<0.001$. 


\subsection{MSNs Provoke ROS Production and Oxidative Stress in the Liver and Kidney of Rats}

ROS, MDA, NO, and antioxidant defenses were determined to evaluate the effect of MSNs on the redox balance in the liver and kidney of rats. ROS were significantly increased in the liver and kidney of rats received $25(p<0.05 ; p<0.01), 50(p<0.5 ; p<0.001), 100(p<0.001 ; p<0.001)$, and $200 \mathrm{mg} / \mathrm{kg}$ $(p<0.001 ; p<0.001)$ MSNs (Figure 3A). MDA was remarkably increased in the liver and kidney of rats following chronic administration of MSNs (Figure 3B). NO was notably increased in the liver and kidney of rats following the administration of MSNs (Figure 3C).

GSH was significantly declined in the liver and kidney of rats that received different doses of MSNs (Figure 3D). SOD and CAT showed a significant $(p<0.001)$ decrease in the liver and kidney of rats administered MSNs (Figure 3E,F, respectively). GPx activity was declined significantly in rats received all doses of MSNs (Figure 3G).

\subsection{MSNs Suppress PPAR $\gamma$ Expression and Nrf2/HO-1 Signaling in Liver and Kidney of Rats}

PPAR $\gamma$ can regulate the expression of antioxidant enzymes [29], and suppress inflammation and fibrosis [22,23]. Therefore, we determined the effect of MSNs on PPAR $\gamma$ expression by western blotting. MSNs suppressed the protein expression levels of PPAR $\gamma$ in the liver and kidney of rats $(p<0.001$; Figure 4A,B). The $50 \mathrm{mg} / \mathrm{kg}$ MSNs down-regulated kidney PPAR $\gamma$ significantly $(p<0.05)$ when compared with the lower dose. In addition, the $100 \mathrm{mg} / \mathrm{kg}$ markedly down-regulated PPAR $\gamma$ expression in the kidney of rats received lower doses.

A

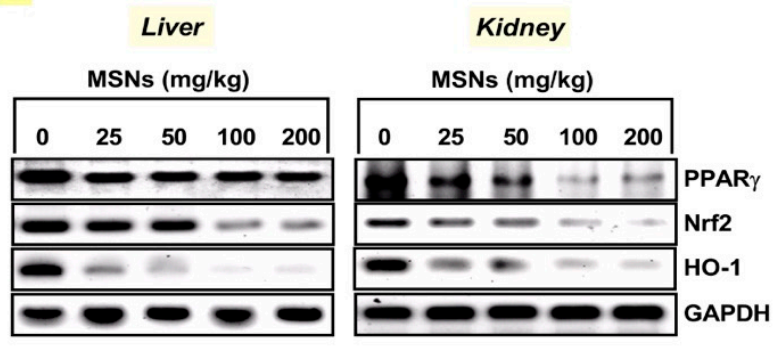

C

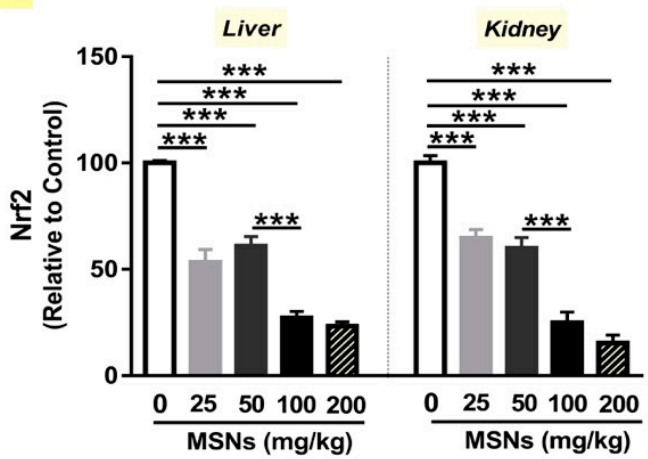

B

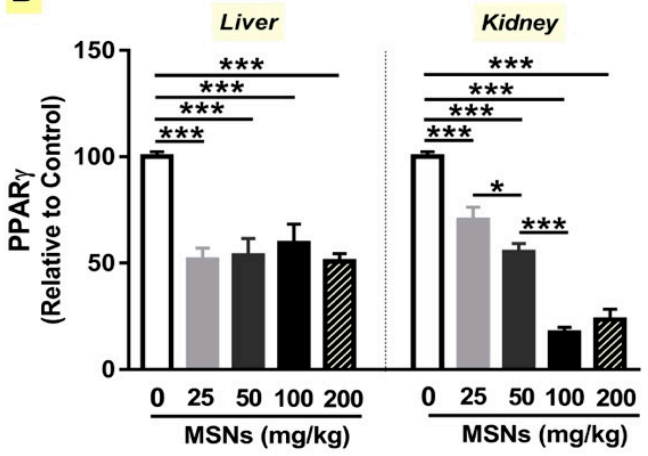

D

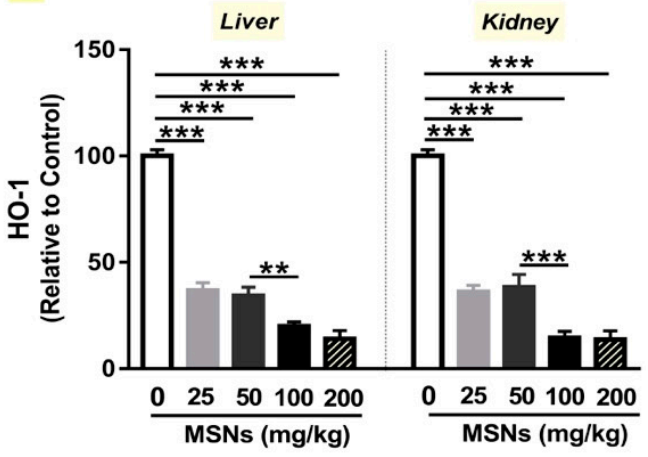

Figure 4. MSNs suppress peroxisome proliferator activated receptor gamma (PPAR $\gamma$ ) expression and nuclear factor erythroid 2-related factor 2 (Nrf2)/heme oxygenase 1 (HO-1) signaling in the liver and kidney of rats. (A) Representative blots of PPAR $\gamma$, Nrf2, and HO-1. (B-D) The expression of PPAR $\gamma$ (B), Nrf2 (C), and HO-1 (D) was significantly decreased in the liver and kidney of MSNs-induced rats. Data are mean $\pm \operatorname{SEM}(n=6) .{ }^{*} p<0.05,{ }^{* *} p<0.01$, and ${ }^{* * *} p<0.001$.

To explore the effect of MSNs on Nrf2 signaling, we determined the protein levels of Nrf2 and HO-1 in the liver and kidney of rats. MSNs reduced Nrf2 and HO-1 expression significantly $(p<0.001$; 
$p<0.001$; Figure 4A,C,D) in both the liver and kidney. When compared with the lower dose, the 100 $\mathrm{mg} / \mathrm{kg}$ MSNs down-regulated the liver and kidney Nrf2 $(p<0.001 ; p<0.001)$ and HO-1 $(p<0.01$; $p<0.001)$.

\subsection{MSNs Activate TLR4/MyD88/NF-кB Signaling and Apoptosis in the Liver and Kidney of Rats}

Given the role of TLR4 activation and its downstream adapter MyD88 in activating the NF-KB signaling pathway [19], we examined the effects of MSNs on TLR4/MyD88/NF-kB signaling. Rats received the lower dose of MSNs exhibited increased expression of TLR4 ( $p<0.001$; Figure 5A,B), MyD88 ( $p<0.05$; Figure 5A,C) and NF-kB p65 ( $p<0.01$; Figure 5A,D). The higher doses increased the protein expression levels of TLR4 (Figure 5B), MYD88 (Figure 5C), and NF-kB p65 (Figure 5D) significantly $(p<0.001)$ in the liver of rats. In the kidney, MSNs activated TLR4/MyD88/NF- $k B$ signaling as revealed by the increased expression of TLR4 (Figure 5A,B), MyD88 (Figure 5A,C), and NF-kB p65 (Figure 5A,D) when administered at the doses of $25(p<0.01 ; p<0.001 ; p<0.05), 50(p<0.05 ; p<0.001$; $p<0.001), 100(p<0.001 ; p<0.001 ; p<0.001)$, and $200 \mathrm{mg} / \mathrm{kg}(p<0.001 ; p<0.001 ; p<0.001)$.

Next, we determined serum levels of pro-inflammatory cytokines. All doses of MSNs increased $(p<0.001)$ the levels of TNF- $\alpha$, IL-1 $\beta$, and IL-6 (Figure 5F).

The apoptosis marker caspase-3 showed a significant increase in the liver and kidney of 50, 100, and $200 \mathrm{mg} / \mathrm{kg}$ MSNs-administered rats (Figure 5A,E). The lower MSNs dose $(25 \mathrm{mg} / \mathrm{kg}$ ) did not activate liver caspase-3 $(p>0.05)$; however, caspase-3 was significantly $(p<0.001)$ activated in the kidney of rats receiving the same dose. 
A

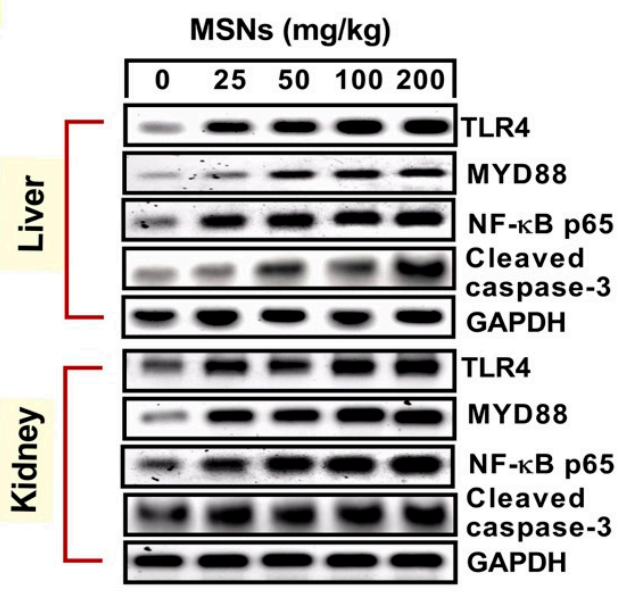

C

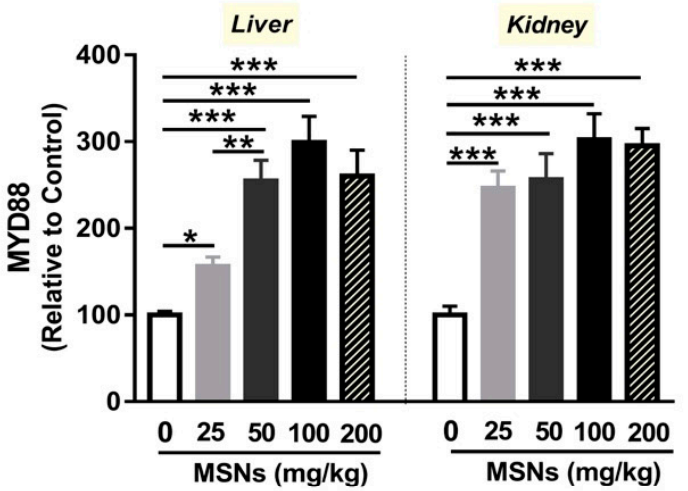

E

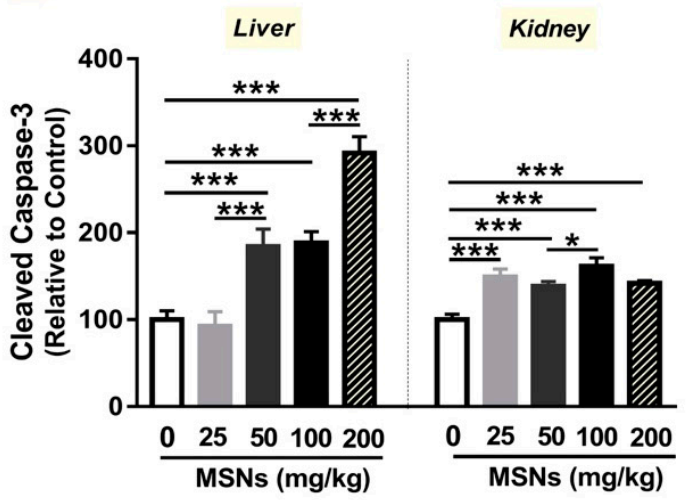

B

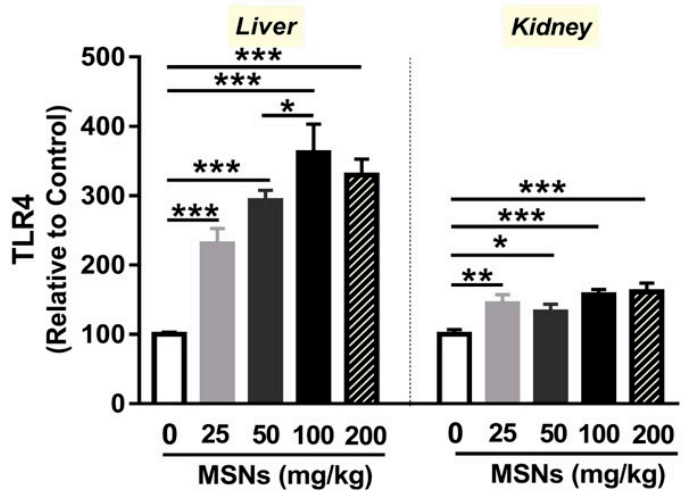

D

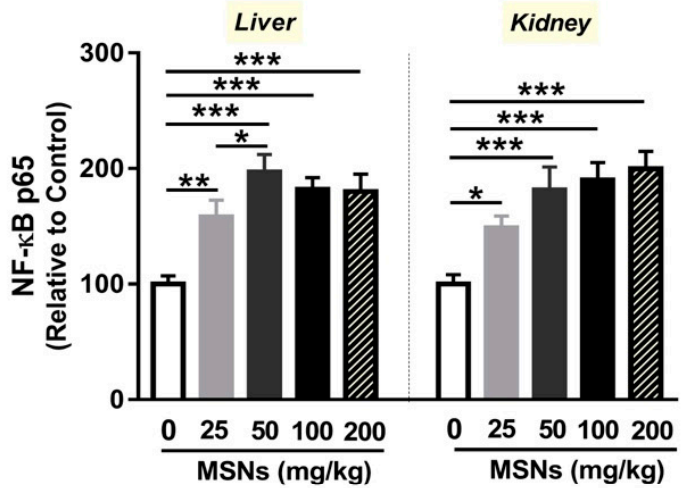

$\mathbf{F}$

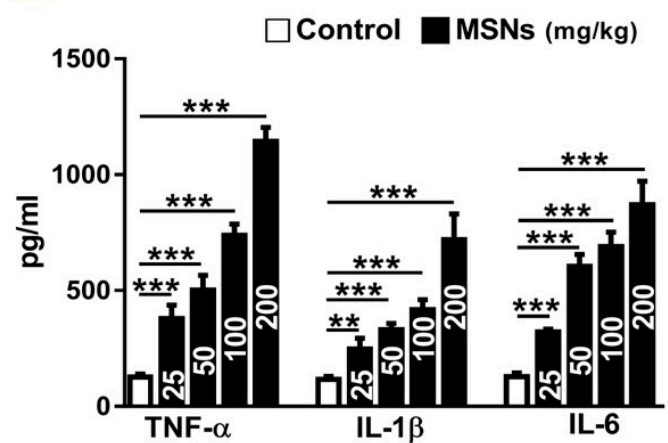

Figure 5. MSNs activate TLR4/MyD88/NF-kB signaling and apoptosis in the liver and kidney of rats. (A) Representative blots of TLR4, MyD88, NF-KB p65, and cleaved caspase-3. MSNs up-regulated TLR4 (B), MyD88 (C), NF-kB p65 (D), and cleaved caspase-3 (E), and increased levels of serum TNF- $\alpha$, IL-1 $\beta$, and IL-6 (F). Data are mean $\pm \operatorname{SEM}(n=6) .{ }^{*} p<0.05,{ }^{* *} p<0.01$, and ${ }^{* * *} p<0.001$.

\subsection{MSNs Induce Liver and Kidney Fibrosis in Rats}

Microscopic examination revealed an increase in the deposition of extracellular matrix (ECM) in the liver (Figure 6A,B) and kidney (Figure 6E,F) of MSNs-induced rats. mRNA expression of collagen I and III was significantly increased in the liver (Figure 6C,D) and kidney (Figure 6G,H) of MSNs-induced rats. 

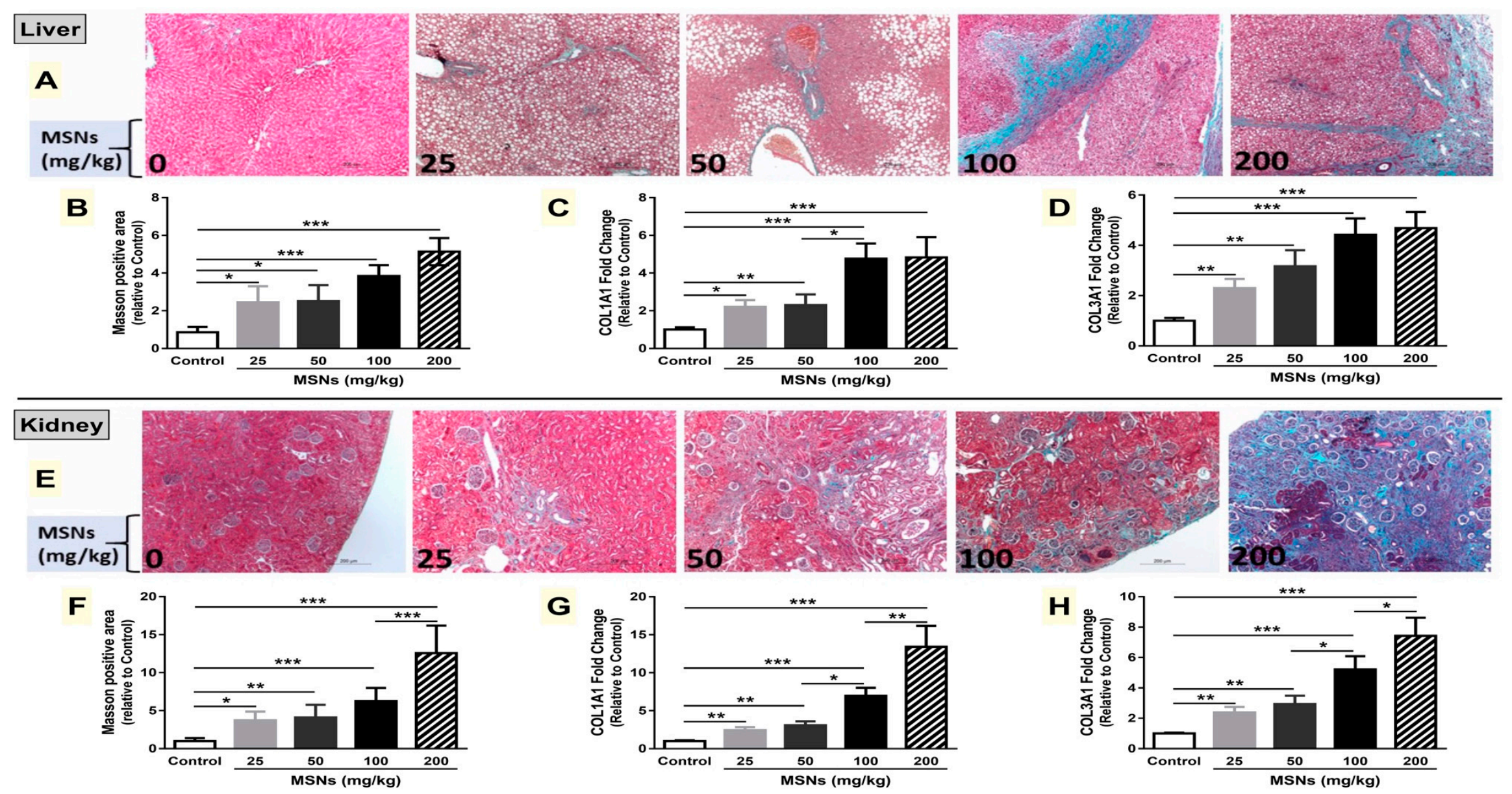

Figure 6. MSNs induce liver and kidney fibrosis in rats. (A,E) Photomicrographs of Masson's trichrome-stained liver (A) and kidney (E) (X100). MSNs induced a significant increase in the deposition of collagen $(\mathbf{B}, \mathbf{F})$ and expression of collagen $\mathrm{I}(\mathbf{C}, \mathbf{G})$ and collagen III $(\mathbf{D}, \mathbf{H})$ in the liver and kidney. Data are mean \pm SEM $(n=6)$. ${ }^{*} p<0.05,{ }^{* *} p<0.01$, and ${ }^{* * *} p<0.001$. 


\subsection{MSNs Activate JAk2/STAT3 Signaling in the Liver and Kidney of Rats}

The pro-inflammatory mediators, notably IL-6, produced as a result of NF-kB activation could bind to its heterodimeric receptor (IL-6R $\alpha$ and IL-6R $\beta$ (gp130)), resulting in transphosphorylation and activation of JAK2. Activated JAK2 phosphorylates STAT3, which homodimerizes and accumulates in the nucleus where it controls the expression of multiple genes. The persistent activation of STAT3 is associated with chronic inflammation and fibrosis [20,21]. Therefore, we investigated the changes in JA2/STAT3 signaling in MSNs-administered rats.

MSNs induced a significant increase in JAK2 and STAT3 phosphorylation and SOCS3 expression (Figure 7A-D) in the liver of rats when administered at doses of $25(p<0.001 ; p<0.05 ; p<0.001), 50$ $(p<0.01 ; p<0.05 ; p<0.001), 100(p<0.01 ; p<0.001 ; p<0.001)$, and $200 \mathrm{mg} / \mathrm{kg}(p<0.01 ; p<0.001$; $p<0.001)$.

A

Liver

MSNs (mg/kg)
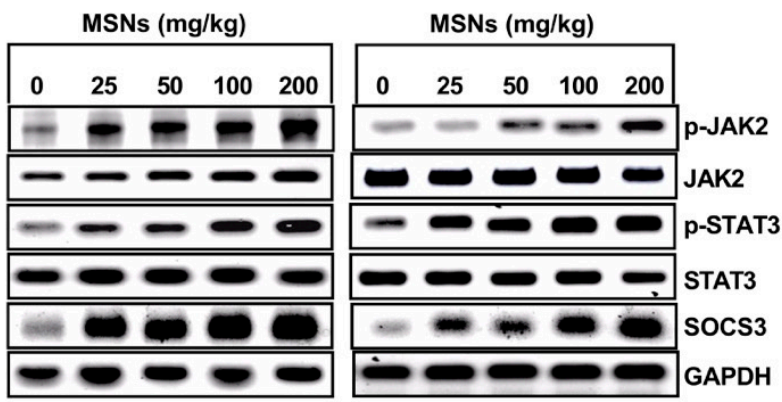

C

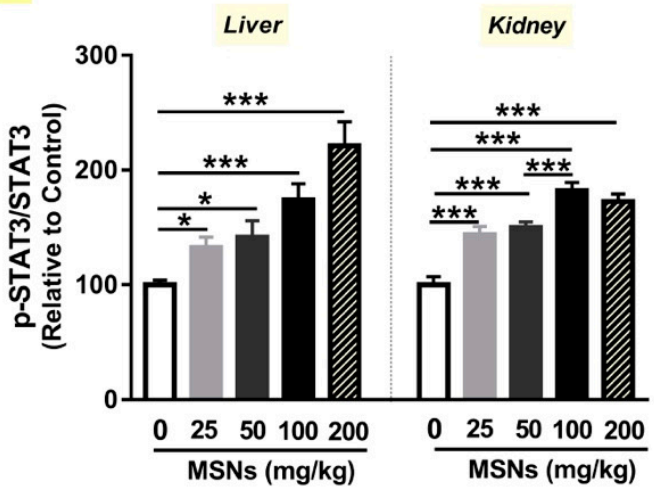

B

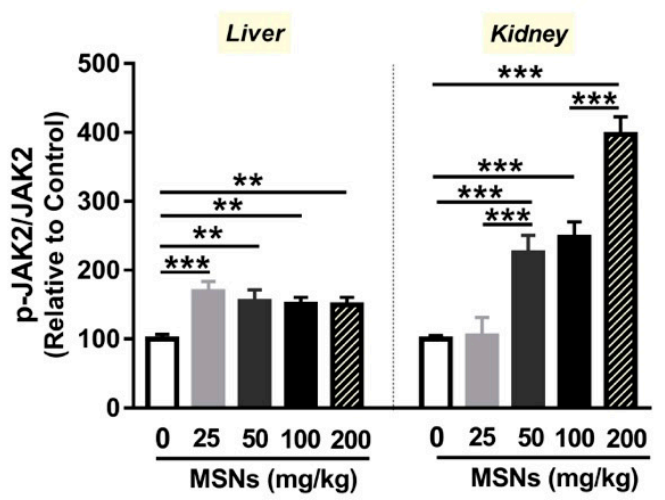

D

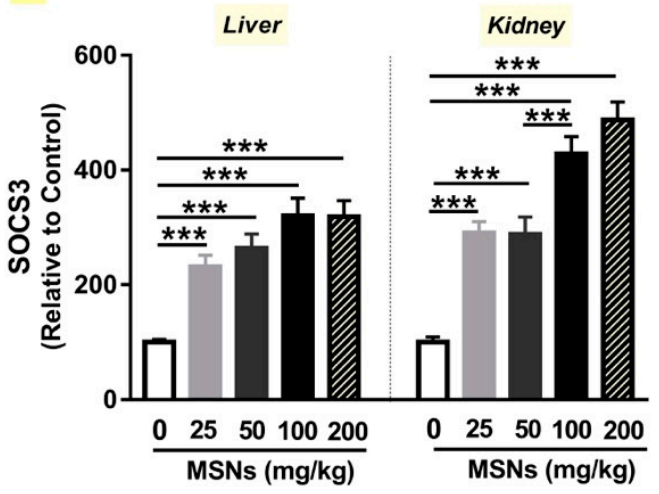

Figure 7. MSNs activate Janus kinase 2/signal transducer and activator of transcription 3 (JAk2/STAT3) signaling in liver and kidney of rats. (A) Representative blots of p-JAK2, JAK2, p-STAT3, STAT3 and SOCS3. MSNs increased phosphorylation levels of JAK2 (B) and STAT3 (C), and the expression of SOCS3 (D). Data are mean $\pm \operatorname{SEM}(n=6) .{ }^{*} p<0.05,{ }^{* *} p<0.01$, and ${ }^{* * *} p<0.001$.

In the kidney of MSNs-induced rats, the effect of the $25 \mathrm{mg} / \mathrm{kg}$ dose on JAK2 phosphorylation was non-significant $(p>0.05)$. However, the same dose significantly increased the phosphorylation of STAT3 $(p<0.001)$ and expression of SOCS3 $(p<0.001)$, as represented in Figure 7A-D. The higher doses induced remarkable $(p<0.001)$ increase in JAK2 and STAT3 phosphorylation and SOCS3 expression in the kidney of rats (Figure 7A-D).

\section{Discussion}

Studies are needed to investigate the mechanisms implicated in the toxicity of MSNs to improve their biomedical applications. In this study, we investigated the mechanisms underlying the hepatic and 
renal toxicity of MSNs in vivo. MSNs induced liver injury evidenced by the dose-dependent increase in ALT, AST, ALP, and bilirubin, along with decreased albumin. Given its role in the recognition and clearance of NPs [30], the liver is vulnerable to SiNPs-induced injury. This notion is supported by studies showing that the largest holder for intravenously administered SiNPs is the liver [31], and the dose-dependent increase in serum ALT in a mouse model of SiNPs-induced acute toxicity [32]. In addition, mice that received $30 \mathrm{mg} / \mathrm{kg}$ SiNPs $(70 \mathrm{~nm})$ exhibited liver injury marked by increased serum ALT and histological alterations, with no effect on the kidney [33]. In contrast, mice that received intragastric MSNs (40 mg/kg) showed normal liver function, whereas creatinine was significantly elevated at day 14 post-administration [34]. Recently, Yu et al. [15] demonstrated elevated serum levels of aminotransferases and decreased albumin in mice receiving $20 \mathrm{mg} / \mathrm{kg}$ amorphous silica NPs, once every three days for 15 days. MSNs-induced liver injury in our study was proved by the histological findings, including degenerative changes, necrosis, fatty changes, congestion, KCs proliferation, leukocyte infiltration in the portal area, and granulomatous reactions. In support of these findings, a recent study demonstrated hydropic degeneration, apoptosis, leukocyte infiltration, central vein hyperemia, and granulomas in mice that received $20 \mathrm{mg} / \mathrm{kg}$ amorphous SiNPs at days 15, 30, and 60 after administration [15]. Moreover, MSNs-induced rats showed nephrotoxicity manifested by the significantly elevated serum creatinine and urea. Accordingly, mice showed increased serum creatinine at day 14 after intragastric administration of $40 \mathrm{mg} / \mathrm{kg}$ MSNs; however, liver function markers were not affected [34]. Histological examination revealed tubular degeneration, glomerulonephritis, glomerular hypercellularity, leukocyte infiltration, and chronic nephritis in $25 \mathrm{mg} / \mathrm{kg}$ MSNs-administered rats. In addition to these manifestations, tubular necrosis was noticed in rats that received $50 \mathrm{mg} / \mathrm{kg}$ MSNs, whereas the higher doses induced glomerular atrophy, tubular dilatation, casts, and cystic, and Bowman's capsule dilatation. In support of these findings, a single ip injection of 300 and $600 \mathrm{mg} / \mathrm{kg}$ MSNs induced lymphocytic infiltration, renal tubular regeneration, and interstitial fibrosis in mice at day 12 post-injection [17]. Our findings pointed to the potential of MSNs to induce liver and kidney functional and structural alterations. However, the mechanisms underlying the toxicity of MSNs are not fully understood.

Recent studies have shown that both oxidative stress and inflammation are implicated in the toxicity of MSNs. Therefore, we determined ROS, MDA, and NO levels, as well as antioxidants in the liver and kidney of MSNs-induced rats. Herein, MSNs promoted a dose-dependent increase in ROS in both the liver and kidney of rats. Excessive production of ROS could provoke lipid peroxidation and damage cellular proteins and DNA. Previous in vitro studies have shown a dose-dependent increase in ROS production in human and rat cell lines treated with SiNPs [35,36]. Recently, we demonstrated increased cardiac and pulmonary ROS in MSNs-induced rats [14]. The potential of SiNPs to induce ROS generation has been attributed to the silicon-bonded hydroxyl groups on the particle surface and the unsaturated bond [37]. As a consequence of excess ROS, MSNs-induced rats exhibited an increase in MDA and diminished GSH and activity of SOD, CAT, and GPx. These findings point to the oxidative stress status provoked by MSNs in the liver and kidney of rats. Yu et al. [15] have recently demonstrated lipid peroxidation and decreased SOD and GPx in mice livers at day 15 after the injection of $20 \mathrm{mg} / \mathrm{kg}$ amorphous SiNPs. In addition, MSNs provoked NO production in both the liver and kidney of rats which could be explained by the increased expression of inducible NO synthase (iNOS) secondary to excessive ROS generation. Previous studies showed accumulation of SiNPs in KCs [15], leading to increased ROS, NO, and expression of pro-inflammatory cytokines [38].

The mechanisms underlying SiNPs-induced production of ROS have been investigated by several authors. Increased ROS in response to SiNPs has been attributed to the intrinsic production by the particles themselves, activation of nicotinamide adenine dinucleotide phosphate (NADPH) oxidase (NOX) and mitochondrial dysfunction [17,39]. Kojima et al. [40] demonstrated increased ATP release from P2X7 receptors in $30 \mathrm{~nm}$ SiNPs-induced KCs in vitro, resulting in increased NOX-mediated ROS generation. In addition, the redox potential sensor transient receptor potential melastatin 2 (TRPM2) has been shown to regulate NOX activity and ROS generation in human embryonic kidney 
293 cells treated with SiNPs [17]. However, studies explored the mechanism of SiNPs-induced ROS generation in vivo are scarce. Herein, we showed the involvement of Nrf2/HO-1 signaling pathway in MSNs-induced overproduction of ROS. Nrf2 is a transcription factor that controls the expression of antioxidants, including HO-1 [41]. Upon exposure to mild oxidative stress, ROS disturbs the Keap1-Cullin 3 ubiquitination system that degrades Nrf2. Consequently, Nrf2 translocate into the nucleus, complex with small MAF and bind to antioxidant response element (ARE), leading to increased expression of antioxidant genes [42]. Therefore, inactivation of Nrf2 signaling can result in diminished antioxidants and increased ROS levels. Our results showed dose-dependent suppression of Nrf2 in MSNs-administered rats. The suppressed Nrf2 signaling was confirmed by the decreased expression of HO-1 along with the diminished antioxidant enzymes in MSNs-administered rats. The suppressed expression of Nrf2 in the present study could be attributed to the excessive and sustained oxidative stress in MSNs-induced rats. This notion is supported by our recent studies where prolonged periods of drug-induced oxidative stress was associated with diminished Nrf2 signaling in the liver and kidney of rodents [43-48].

Inflammation is an important element in the evaluation of NPs toxicity. MSNs activated NF- $\mathrm{B}$ and subsequently increased the release of TNF- $\alpha$, IL- $1 \beta$, and IL-6. NF- $\mathrm{KB}$ has a prominent role in inflammation and oxidative stress, and some in vitro and in vivo studies demonstrated its activation in response to SiNPs $[16,17]$. In addition to ROS, TLR4 activation and MyD88 play an important role in the activation of NF-KB [19]. Therefore, we thought that the TLR4/MyD88/NF-KB signaling might be implicated in MSNs-induced liver and kidney injury. Our findings showed increased expression of TLR4 and MyD88 in MSNs-administered rats. TLRs are widely expressed in different cells, including KCs, hepatocytes, and hepatic stellate cells (HSCs), and TLRs-mediated signaling has been involved in liver and kidney diseases $[49,50]$. Given that TLR4 could be stimulated by endotoxins, we tested our MSNs samples to exclude any endotoxin contamination. Therefore, our study introduced evidence that TLR4/MyD88/NF- $\mathrm{KB}$ signaling is one of the pathways implicated in MSNs-induced liver and kidney injury. Furthermore, MSNs-induced suppression of Nrf2 could be implicated in the activation of NF- $k \mathrm{~B}$ signaling. Nrf2 diminishes oxidative stress and NF- $\mathrm{kB}[43,44]$; therefore, the loss of Nrf2 function elicits oxidative stress and amplifies inflammation. In addition, overexpression of the NF- $\kappa B$ p65 subunit could increase the abundance of nuclear Keap1, resulting in inhibition of Nrf2 signaling [51]; however, the capability of Keap1 to deactivate Nrf2 within the nucleus is debated [52]. Besides its ability to suppresses inflammation through redox control, Nrf2 has been identified as an upstream regulator of pro-inflammatory cytokine production [53]. Nrf2 suppressed both in vitro and in vivo macrophage inflammatory response independently of the Nrf2-binding motif and ROS level [53].

Several studies have demonstrated the potential of SiNPs to induce liver fibrosis [15,54]. Here, we showed that MSNs induced fibrosis in both the liver and kidney of rats as evidenced by the MT staining and the expression of collagen. In accordance with our findings, oral exposure to 100, 500, or $1000 \mathrm{mg} / \mathrm{kg}$ nanostructured silica for 84 days up-regulated the fibrosis-related genes in the liver of rats [54]. Mice received repeated intravenous administration of 15, 30, or $60 \mathrm{mg} / \mathrm{kg}$ SiNPs showed increased deposition of collagen mediated via activation of TGF- $\beta 1 / \mathrm{Smad} 3$ signaling in the liver [15]. In addition, mice received an ip high dose of MSNs showed renal interstitial fibrosis mediated via activation of NF- $\mathrm{kB}$ signaling [17]. TGF- $\beta$ is a core pathway of fibrosis, and activation of TGF- $\beta 1 / \mathrm{Smad} 3$ signaling increases the expression of pro-fibrotic genes [55]. We have recently reported up-regulation of TGF- $\beta 1 / \mathrm{Smad} 3$ signaling associated with inflammation and fibrosis in the liver of rats [56]. To explore the mechanism underlying MSNs-induced liver and kidney fibrosis in rats, we investigated the role of JAK2/STAT3 signaling. In addition to its role in inflammation, we hypothesized that STAT3 might be implicated in MSNs-induced fibrosis. Herein, MSNs promoted JAK2 and STAT3 phosphorylation in the liver and kidney of rats. Although it has an important role in cell survival and proliferation, persistent activation of STAT3 is associated with various pathological conditions, including fibrosis $[20,21]$. The molecular mechanisms of the involvement of STAT3 in fibrosis are not fully elucidated; however, there is evidence that STAT3 induces the production of collagen type I [57]. 
Our results added support to this notion where activation of JAK2/STAT3 signaling was associated with up-regulation of collagen I and III expression. Recently, STAT3 has been reported to control COL1A2 enhancer activation directly [57]. Other studies have attributed TGF $\beta$-induced increase in collagen production to STAT3. In this context, TGF- $\beta$-mediated phosphorylation of STAT3 at S727 is involved in the fibrotic element of fibrostenotic Crohn's disease [58]. Inhibition of STAT3 signaling in fibrotic kidney cells suppressed the expression of collagen I and other fibrosis mediators, independently of Smad3 [59]. In addition, STAT3 can control the expression of matrix metalloproteinases (MMPs) which play a key role in the maintenance of the ECM. In a model of renal fibrosis, activation of STAT3 was associated with the up-regulation of MMP-9 [60]. Furthermore, JAK2 has previously been demonstrated as a mediator of non-canonical TGF $\beta$ signaling [61]. Recently, Chakraborty et al. [62] have shown that STAT3 acts as a mediator of the pro-fibrotic effects of TGF- $\beta$. In cultured fibroblasts, siRNA-induced knockdown and pharmacological inhibition of STAT3 diminished TGF $\beta$-induced differentiation, as well as collagen release [62]. Therefore, activation of JAK2/STAT3 signaling and subsequent collagen production contributes significantly to MSNs-induced liver and kidney fibrosis in rats.

Owing to the association between ROS, inflammatory cytokines, and apoptosis, and the growing evidence pointing to the role of apoptosis in fibrogenesis $[15,63,64]$, we determined cleaved caspase-3 expression in MSNs-induced rats. Here, we observed an increase in liver and kidney cleaved caspase-3 in rats received different doses of MSNs. Inhibition of caspase-mediated apoptosis has been reported as an effective strategy to ameliorate murine lung fibrosis [63]. In the liver, apoptotic hepatocytes are rapidly engulfed by $\mathrm{KCs}$, and the accumulation of apoptotic bodies triggers the production of TNF- $\alpha$ and the release of TGF- $\beta 1$ from HSCs, resulting in hepatic inflammation, extended apoptosis of hepatocytes and fibrosis [64,65]. Therefore, persistent apoptosis is one of the factors implicated in MSNs-induced liver and kidney fibrosis.

PPAR $\gamma$ could directly activate the expression of antioxidant enzymes [29], and suppress NF-кB [22] and TGF- $\beta 1 / S m a d 3$ [23]. Therefore, we hypothesized that it might have a role in the MSNs-induced oxidative stress, inflammation, and fibrosis. Interestingly, PPAR $\gamma$ was down-regulated in MSNs-induced rats. Studies have shown remarkable liver fibrosis in PPAR $\gamma$-deficient mice and suppressed HSCs and fibrogenesis following PPAR $\gamma$ overexpression [66]. PPAR $\gamma$ can bind Smad3 and suppress the nuclear accumulation of $\mathrm{p}-\mathrm{Smad} 3$ and TGF- $\beta 1$ signaling [23]. Pharmacologic activation of PPAR $\gamma$ inhibited dermal fibrogenesis by suppressing the early growth response protein 1 , a mediator of non-Smad TGF- $\beta 1$ signaling [24], and maintained normal epithelial phenotype, prevented renal fibrosis and oxidative stress in mice [67]. Our findings offer the first evidence showing the role of PPAR $\gamma$ in MSNs-induced liver and kidney injury.

\section{Conclusions}

Our findings show that MSNs have the potential to induce a dose-dependent liver and kidney injury in rats. The impaired function of the liver and kidney was mediated via MSNs-induced oxidative stress, inflammation, fibrosis, and tissue injury. The obtained data conferred new information on the involvement of activated TLR4/MyD88/NF- $\mathrm{BB}$ and JAK2/STAT3 signaling and suppressed the Nrf2/ARE/HO-1 pathway in mediating the in vivo toxicity of MSNs. Furthermore, this study pointed to the ability of MSNs to suppress PPAR $\gamma$ expression in the liver and kidney of rats (summarized mechanistic pathways are represented in Figure 8). Together, the findings of this study enriched our understanding of the mechanisms implicated in the toxicity of MSNs. However, further studies employing genetic and pharmacological strategies are needed to delineate the exact involvement of these signaling pathways in MSNs toxicity. Understanding the exact mechanisms underlying its toxicity will provide strategies for the production of MSNs with minimum or no toxic effects and improve their biomedical application. 


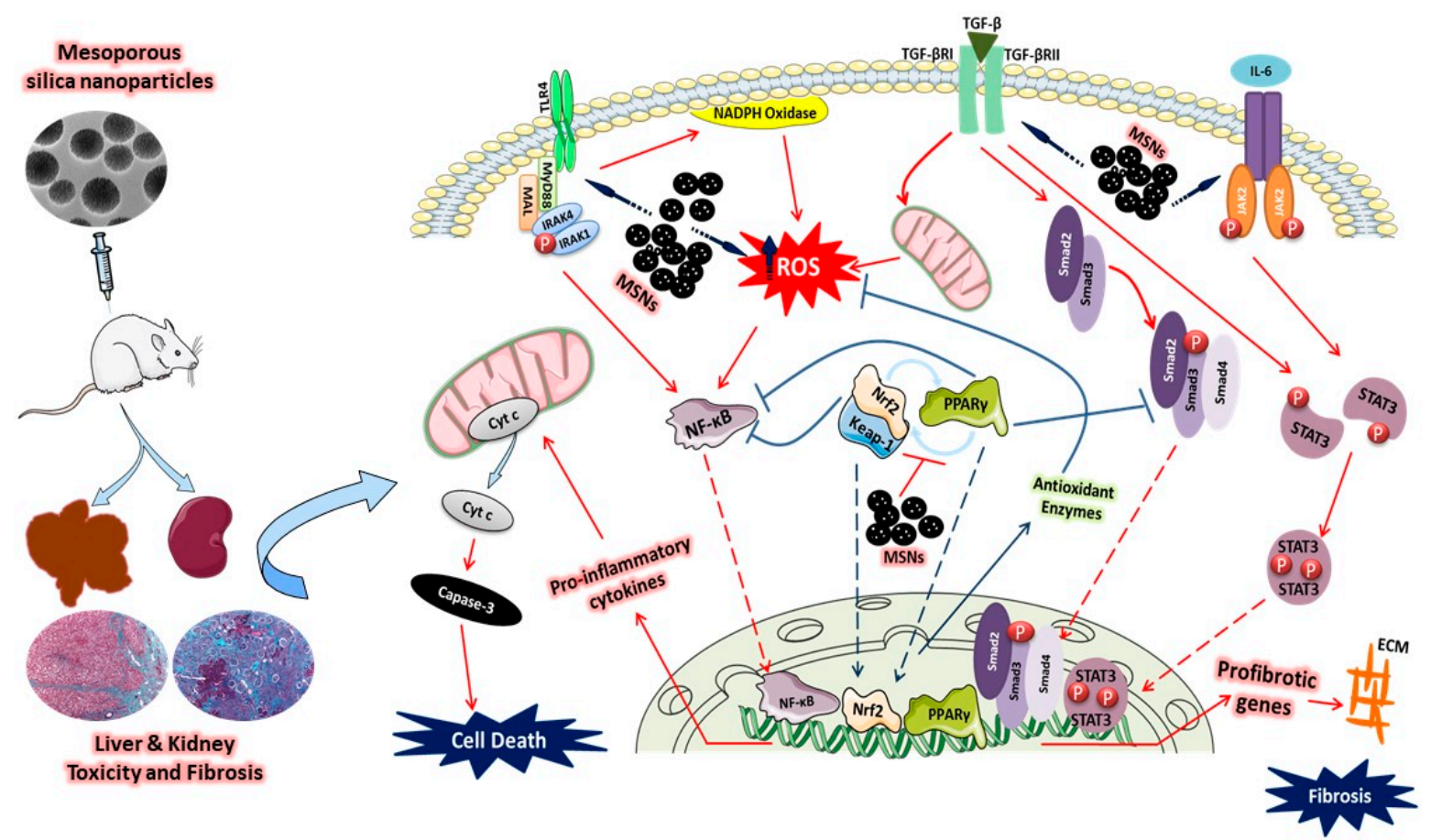

Figure 8. A proposed schematic diagram illustrating MSNs-induced hepatic and renal toxicity and fibrosis. MSNs provoke the production of ROS through the intrinsic production, mitochondrial dysfunction, and stimulation of NADPH oxidase, and activate the TLR4/MyD88 signaling. ROS and elicited TLR4/MyD88 signaling activates NF- $\mathrm{BB}$, and subsequently the release of pro-inflammatory cytokines, resulting in apoptotic cell death via activation of caspase-3. MSNs activate both TGF- $\beta / S \operatorname{Smad} 3$ and JAK2/STAT3 signaling, increase the transcription of profibrotic genes, and promote deposition of ECM and fibrosis. The increased ROS production, inflammation, and fibrosis induced by MSNs are augmented by the down-regulation of PPAR $\gamma$ and Nrf2/ARE/HO-1 signaling.

Supplementary Materials: The following are available online at http://www.mdpi.com/2218-273X/9/10/528/s1, Figure S1: Characterization of MSNs.; Methods: Synthesis and characterization of MSNs.

Author Contributions: Conceptualization-A.M.M.; investigation-A.M.M. and E.M.D; methodology-A.M.M. and A.A.F.; validation-A.M.M.; H.A.S.; A.A.F. and W.G.H.; formal analysis-A.M.M.; visualization-A.M.M.; resources-M.B-J. and A.M.M.; data curation-A.M.M. and E.-S.E.-N.; writing-original draft preparation-A.M.M.; writing-review and editing-A.M.M.; supervision-A.M.M.; project administration-A.M.M. and A.A.F.; funding acquisition-A.M.M.; A.A.F.; W.G.H.; E.-S.E.-N. and E.M.D.

Funding: This research was funded by the Projects Funding and Granting Unit, Beni-Suef University (Egypt).

Acknowledgments: The authors would like to thank the Projects Funding and Granting Unit, Beni-Suef University (Egypt) for supporting this study.

Conflicts of Interest: The authors declare no conflict of interest.

\section{References}

1. Zhou, Y.; Quan, G.; Wu, Q.; Zhang, X.; Niu, B.; Wu, B.; Huang, Y.; Pan, X.; Wu, C. Mesoporous silica nanoparticles for drug and gene delivery. Acta Pharm. Sin. B 2018, 8, 165-177. [CrossRef] [PubMed]

2. Brinch, A.; Hansen, S.F.; Hartmann, N.B.; Baun, A. Eu regulation of nanobiocides: Challenges in implementing the biocidal product regulation (BPR). Nanomaterials 2016, 6, 33. [CrossRef] [PubMed]

3. Murugadoss, S.; Lison, D.; Godderis, L.; Van Den Brule, S.; Mast, J.; Brassinne, F.; Sebaihi, N.; Hoet, P.H. Toxicology of silica nanoparticles: An update. Arch. Toxicol. 2017, 91, 2967-3010. [CrossRef] [PubMed]

4. Dekkers, S.; Krystek, P.; Peters, R.J.; Lankveld, D.P.; Bokkers, B.G.; van Hoeven-Arentzen, P.H.; Bouwmeester, H.; Oomen, A.G. Presence and risks of nanosilica in food products. Nanotoxicology 2011, 5, 393-405. [CrossRef] [PubMed] 
5. Younes, M.; Aggett, P.; Aguilar, F.; Crebelli, R.; Dusemund, B.; Filipič, M.; Frutos, M.J.; Galtier, P.; Galtier, P.; Gott, D.; et al. Re-evaluation of silicon dioxide (E 551) as a food additive. EFSA J. 2018, 16, e05088.

6. Croissant, J.G.; Fatieiev, Y.; Khashab, N.M. Degradability and clearance of silicon, organosilica, silsesquioxane, silica mixed oxide, and mesoporous silica nanoparticles. Adv. Mater. 2017, 29, 1604634. [CrossRef] [PubMed]

7. Singh, R.K.; Patel, K.D.; Leong, K.W.; Kim, H.W. Progress in nanotheranostics based on mesoporous silica nanomaterial platforms. ACS Appl. Mater. Interfaces 2017, 9, 10309-10337. [CrossRef] [PubMed]

8. Trewyn, B.G.; Giri, S.; Slowing, I.I.; Lin, V.S.Y. Mesoporous silica nanoparticle based controlled release, drug delivery, and biosensor systems. Chem. Commun. 2007, 31, 3236-3245. [CrossRef]

9. Lee, S.B.; Kim, H.L.; Jeong, H.J.; Lim, S.T.; Sohn, M.H.; Kim, D.W. Mesoporous silica nanoparticle pretargeting for pet imaging based on a rapid bioorthogonal reaction in a living body. Angew. Chem. Int. Ed. 2013, 52, 10549-10552. [CrossRef]

10. Jafari, S.; Derakhshankhah, H.; Alaei, L.; Fattahi, A.; Varnamkhasti, B.S.; Saboury, A.A. Mesoporous silica nanoparticles for therapeutic/diagnostic applications. Biomed. Pharmacother. 2019, 109, 1100-1111. [CrossRef]

11. Rascol, E.; Pisani, C.; Dorandeu, C.; Nyalosaso, J.L.; Charnay, C.; Daurat, M.; Da Silva, A.; Devoisselle, J.-M.; Gaillard, J.-C.; Armengaud, J.; et al. Biosafety of mesoporous silica nanoparticles. Biomimetics 2018, 3, 22. [CrossRef]

12. Chen, L.; Liu, J.; Zhang, Y.; Zhang, G.; Kang, Y.; Chen, A.; Feng, X.; Shao, L. The toxicity of silica nanoparticles to the immune system. Nanomedicine 2018, 13, 1939-1962. [CrossRef]

13. Leung, C.C.; Yu, I.T.; Chen, W. Silicosis. Lancet 2012, 379, 2008-2018. [CrossRef]

14. Hozayen, W.G.; Mahmoud, A.M.; Desouky, E.M.; El-Nahass, E.-S.; Soliman, H.A.; Farghali, A.A. Cardiac and pulmonary toxicity of mesoporous silica nanoparticles is associated with excessive ros production and redox imbalance in wistar rats. Biomed. Pharmacother. 2019, 109, 2527-2538. [CrossRef]

15. Yu, Y.; Duan, J.; Li, Y.; Li, Y.; Jing, L.; Yang, M.; Wang, J.; Sun, Z. Silica nanoparticles induce liver fibrosis via TGF- $3(1) / S m a d 3$ pathway in icr mice. Int. J. Nanomed. 2017, 12, 6045-6057. [CrossRef]

16. Waters, K.M.; Masiello, L.M.; Zangar, R.C.; Tarasevich, B.J.; Karin, N.J.; Quesenberry, R.D.; Bandyopadhyay, S.; Teeguarden, J.G.; Pounds, J.G.; Thrall, B.D. Macrophage responses to silica nanoparticles are highly conserved across particle sizes. Toxicol. Sci. Off. J. Soc. Toxicol. 2009, 107, 553-569. [CrossRef]

17. Chen, X.; Zhouhua, W.; Jie, Z.; Xinlu, F.; Jinqiang, L.; Yuwen, Q.; Zhiying, H. Renal interstitial fibrosis induced by high-dose mesoporous silica nanoparticles via the NF-kB signaling pathway. Int. J. Nanomed. 2015, 10, 1-22. [CrossRef]

18. Ahmed, S.M.; Luo, L.; Namani, A.; Wang, X.J.; Tang, X. Nrf2 signaling pathway: Pivotal roles in inflammation. Biochim. Biophys. Acta Mol. Basis Dis. 2017, 1863, 585-597. [CrossRef]

19. Winkler, H.C.; Kornprobst, J.; Wick, P.; von Moos, L.M.; Trantakis, I.; Schraner, E.M.; Bathke, B.; Hochrein, H.; Suter, M.; Naegeli, H. MyD88-dependent pro-interleukin-1 $\beta$ induction in dendritic cells exposed to food-grade synthetic amorphous silica. Part. Fibre Toxicol. 2017, 14, 21. [CrossRef]

20. Levy, D.E.; Darnell, J.E., Jr. Stats: Transcriptional control and biological impact. Nat. Rev. Mol. Cell Biol. 2002, 3, 651-662. [CrossRef]

21. Ogata, H.; Chinen, T.; Yoshida, T.; Kinjyo, I.; Takaesu, G.; Shiraishi, H.; Iida, M.; Kobayashi, T.; Yoshimura, A. Loss of SOCS3 in the liver promotes fibrosis by enhancing STAT3-mediated TGF- $\beta 1$ production. Oncogene 2006, 25, 2520-2530. [CrossRef] [PubMed]

22. Ricote, M.; Huang, J.T.; Welch, J.S.; Glass, C.K. The peroxisome proliferator-activated receptor (PPAR $\gamma$ ) as a regulator of monocyte/macrophage function. J. Leukoc. Biol. 1999, 66, 733-739. [CrossRef] [PubMed]

23. Lin, L.C.; Hsu, S.L.; Wu, C.L.; Liu, W.C.; Hsueh, C.M. Peroxisome proliferator-activated receptor gamma $(\operatorname{PPAR} \gamma)$ plays a critical role in the development of tgfbeta resistance of H460 cell. Cell. Signal. 2011, 23, 1640-1650. [CrossRef] [PubMed]

24. Wu, M.; Melichian, D.S.; Chang, E.; Warner-Blankenship, M.; Ghosh, A.K.; Varga, J. Rosiglitazone abrogates bleomycin-induced scleroderma and blocks profibrotic responses through peroxisome proliferator-activated receptor-gamma. Am. J. Pathol. 2009, 174, 519-533. [CrossRef] [PubMed]

25. AbouAitah, K.; Swiderska-Sroda, A.; Farghali, A.A.; Wojnarowicz, J.; Stefanek, A.; Gierlotka, S.; Opalinska, A.; Allayeh, A.K.; Ciach, T.; Lojkowski, W. Folic acid-conjugated mesoporous silica particles as nanocarriers of natural prodrugs for cancer targeting and antioxidant action. Oncotarget 2018, 9, 26466-26490. [CrossRef] [PubMed] 
26. Mahmoud, A.M.; Wilkinson, F.L.; Jones, A.M.; Wilkinson, J.A.; Romero, M.; Duarte, J.; Alexander, M.Y. A novel role for small molecule glycomimetics in the protection against lipid-induced endothelial dysfunction: Involvement of akt/enos and Nrf2/are signaling. Biochim. Biophys. Acta 2017, 1861, 3311-3322. [CrossRef]

27. Livak, K.J.; Schmittgen, T.D. Analysis of relative gene expression data using real-time quantitative PCR and the $2^{-\triangle \Delta C T}$ method. Methods 2011, 25, 402-408. [CrossRef] [PubMed]

28. Schneider, C.A.; Rasband, W.S.; Eliceiri, K.W. NIH Image to ImageJ: 25 years of image analysis. Nat. Methods 2012, 9, 671-675. [CrossRef]

29. Okuno, Y.; Matsuda, M.; Kobayashi, H.; Morita, K.; Suzuki, E.; Fukuhara, A.; Komuro, R.; Shimabukuro, M.; Shimomura, I. Adipose expression of catalase is regulated via a novel remote PPAR $\gamma$-responsive region. Biochem. Biophys. Res. Commun. 2008, 366, 698-704. [CrossRef]

30. Linkov, I.; Satterstrom, F.K.; Corey, L.M. Nanotoxicology and nanomedicine: Making hard decisions. Nanomed. Nanotechnol. Biol. Med. 2008, 4, 167-171. [CrossRef]

31. Kumar, R.; Roy, I.; Ohulchanskky, T.Y.; Vathy, L.A.; Bergey, E.J.; Sajjad, M.; Prasad, P.N. In vivo biodistribution and clearance studies using multimodal organically modified silica nanoparticles. ACS Nano 2010, 4, 699-708. [CrossRef] [PubMed]

32. Yu, Y.; Li, Y.; Wang, W.; Jin, M.; Du, Z.; Li, Y.; Duan, J.; Yu, Y.; Sun, Z. Acute toxicity of amorphous silica nanoparticles in intravenously exposed ICR mice. PLoS ONE 2013, 8, e61346. [CrossRef] [PubMed]

33. Nishimori, H.; Kondoh, M.; Isoda, K.; Tsunoda, S.; Tsutsumi, Y.; Yagi, K. Silica nanoparticles as hepatotoxicants. Eur. J. Pharm. Biopharm. 2009, 72, 496-501. [CrossRef] [PubMed]

34. Li, L.; Liu, T.; Fu, C.; Tan, L.; Meng, X.; Liu, H. Biodistribution, excretion, and toxicity of mesoporous silica nanoparticles after oral administration depend on their shape. Nanomed. Nanotechnol. Biol. Med. 2015, 11, 1915-1924. [CrossRef] [PubMed]

35. Sun, L.; Li, Y.; Liu, X.; Jin, M.; Zhang, L.; Du, Z.; Guo, C.; Huang, P.; Sun, Z. Cytotoxicity and mitochondrial damage caused by silica nanoparticles. Toxicol. In Vitro 2011, 25, 1619-1629. [CrossRef] [PubMed]

36. Zuo, D.; Duan, Z.; Jia, Y.; Chu, T.; He, Q.; Yuan, J.; Dai, W.; Li, Z.; Xing, L.; Wu, Y. Amphipathic silica nanoparticles induce cytotoxicity through oxidative stress mediated and p53 dependent apoptosis pathway in human liver cell line HL-7702 and rat liver cell line BRL-3a. Colloids Surf. B Biointerfaces 2016, 145, 232-240. [CrossRef] [PubMed]

37. Napierska, D.; Thomassen, L.C.; Lison, D.; Martens, J.A.; Hoet, P.H. The nanosilica hazard: Another variable entity. Part. Fibre Toxicol. 2010, 7, 39. [CrossRef]

38. Xue, Y.; Chen, Q.; Ding, T.; Sun, J. Sio(2) nanoparticle-induced impairment of mitochondrial energy metabolism in hepatocytes directly and through a kupffer cell-mediated pathway in vitro. Int. J. Nanomed. 2014, 9, 2891-2903.

39. Fubini, B.; Hubbard, A. Reactive oxygen species (ROS) and reactive nitrogen species (RNS) generation by silica in inflammation and fibrosis. Free Radic. Biol. Med. 2003, 34, 1507-1516. [CrossRef]

40. Kojima, S.; Negishi, Y.; Tsukimoto, M.; Takenouchi, T.; Kitani, H.; Takeda, K. Purinergic signaling via p2x7 receptor mediates IL-1 $\beta$ production in kupffer cells exposed to silica nanoparticle. Toxicology 2014, 321, 13-20. [CrossRef]

41. Satta, S.; Mahmoud, A.M.; Wilkinson, F.L.; Yvonne Alexander, M.; White, S.J. The role of NrfF2 in cardiovascular function and disease. Oxidative Med. Cell. Longev. 2017, 2017, 9237263. [CrossRef] [PubMed]

42. Itoh, K.; Chiba, T.; Takahashi, S.; Ishii, T.; Igarashi, K.; Katoh, Y.; Oyake, T.; Hayashi, N.; Satoh, K.; Hatayama, I. An Nrf2/small maf heterodimer mediates the induction of phase II detoxifying enzyme genes through antioxidant response elements. Biochem. Biophys. Res. Commun. 1997, 236, 313-322. [CrossRef] [PubMed]

43. Mahmoud, A.M.; Germoush, M.O.; Al-Anazi, K.M.; Mahmoud, A.H.; Farah, M.A.; Allam, A.A. Commiphora molmol protects against methotrexate-induced nephrotoxicity by up-regulating Nrf2/ARE/HO-1 signaling. Biomed. Pharmacother. 2018, 106, 499-509. [CrossRef] [PubMed]

44. Mahmoud, A.M.; Hussein, O.E.; Hozayen, W.G.; Abd El-Twab, S.M. Methotrexate hepatotoxicity is associated with oxidative stress, and down-regulation of PPAR $\gamma$ and Nrf2: Protective effect of 18beta-glycyrrhetinic acid. Chem. Biol. Interact. 2017, 270, 59-72. [CrossRef] [PubMed]

45. Mahmoud, A.M.; Zaki, A.R.; Hassan, M.E.; Mostafa-Hedeab, G. Commiphora molmol resin attenuates diethylnitrosamine/phenobarbital-induced hepatocarcinogenesis by modulating oxidative stress, inflammation, angiogenesis and Nrf2/ARE/HO-1 signaling. Chem. Biol. Interact. 2017, 270, 41-50. [CrossRef] [PubMed] 
46. ALHaithloul, H.A.S.; Alotaibi, M.F.; Bin-Jumah, M.; Elgebaly, H.; Mahmoud, A.M. Olea europaea leaf extract up-regulates Nrf2/ARE/HO-1 signaling and attenuates cyclophosphamide-induced oxidative stress, inflammation and apoptosis in rat kidney. Biomed. Pharmacother. 2019, 111, 676-685. [CrossRef]

47. Mahmoud, A.M.; Hussein, O.E.; Abd El-Twab, S.M.; Hozayen, W.G. Ferulic acid protects against methotrexate nephrotoxicity via activation of Nrf2/ARE/HO-1 signaling and PPAR $\gamma$, and suppression of NF-kB/NLRP3 inflammasome axis. Food Funct. 2019, 10, 4593-4607. [CrossRef]

48. Aladaileh, S.H.; Abukhalil, M.H.; Saghir, S.A.M.; Hanieh, H.; Alfwuaires, M.A.; Almaiman, A.A.; Bin-Jumah, M.; Mahmoud, A.M. Galangin activates Nrf2 signaling and attenuates oxidative damage, inflammation, and apoptosis in a rat model of cyclophosphamide-induced hepatotoxicity. Biomolecules 2019, 9, 346. [CrossRef]

49. Xu, J.; Zhang, X.; Monestier, M.; Esmon, N.L.; Esmon, C.T. Extracellular histones are mediators of death through TLR2 and TLR4 in mouse fatal liver injury. J. Immunol. 2011, 187, 2626-2631. [CrossRef]

50. Smith, K.D. Toll-like receptors in kidney disease. Curr. Opin. Nephrol. Hypertens. 2009, 18, $189-196$. [CrossRef]

51. Yu, M.; Li, H.; Liu, Q.; Liu, F.; Tang, L.; Li, C.; Yuan, Y.; Zhan, Y.; Xu, W.; Li, W.; et al. Nuclear factor p65 interacts with keap1 to repress the Nrf2-are pathway. Cell. Signal. 2011, 23, 883-892. [CrossRef]

52. Wardyn, J.D.; Ponsford, A.H.; Sanderson, C.M. Dissecting molecular cross-talk between Nrf2 and NF-kB response pathways. Biochem. Soc. Trans. 2015, 43, 621-626. [CrossRef] [PubMed]

53. Kobayashi, E.H.; Suzuki, T.; Funayama, R.; Nagashima, T.; Hayashi, M.; Sekine, H.; Tanaka, N.; Moriguchi, T.; Motohashi, H.; Nakayama, K.; et al. Nrf2 suppresses macrophage inflammatory response by blocking proinflammatory cytokine transcription. Nat. Commun. 2016, 7, 11624. [CrossRef] [PubMed]

54. Van der Zande, M.; Vandebriel, R.J.; Groot, M.J.; Kramer, E.; Herrera Rivera, Z.E.; Rasmussen, K.; Ossenkoppele, J.S.; Tromp, P.; Gremmer, E.R.; Peters, R.J.B.; et al. Sub-chronic toxicity study in rats orally exposed to nanostructured silica. Part. Fibre Toxicol. 2014, 11, 8. [CrossRef] [PubMed]

55. Dooley, S.; ten Dijke, P. TGF- $\beta$ in progression of liver disease. Cell Tissue Res. 2012, 347, 245-256. [CrossRef]

56. Mahmoud, A.M.; Hozayen, W.G.; Hasan, I.H.; Shaban, E.; Bin-Jumah, M. Umbelliferone ameliorates CCL4-induced liver fibrosis in rats by upregulating PPAR $\gamma$ and attenuating oxidative stress, inflammation, and TGF- $\beta 1 /$ Smad3 signaling. Inflammation 2019, 42, 1103-1116. [CrossRef] [PubMed]

57. Papaioannou, I.; Xu, S.; Denton, C.P.; Abraham, D.J.; Ponticos, M. Stat3 controls COL1A2 enhancer activation cooperatively with junb, regulates type i collagen synthesis posttranscriptionally, and is essential for lung myofibroblast differentiation. Mol. Biol. Cell 2018, 29, 84-95. [CrossRef]

58. Li, C.; Iness, A.; Yoon, J.; Grider, J.R.; Murthy, K.S.; Kellum, J.M.; Kuemmerle, J.F. Noncanonical Stat3 activation regulates excess TGF- $\beta 1$ and collagen i expression in muscle of stricturing crohn's disease. J. Immunol. 2015, 194, 3422-3431. [CrossRef]

59. Seo, H.Y.; Jeon, J.H.; Jung, Y.A.; Jung, G.S.; Lee, E.J.; Choi, Y.K.; Park, K.G.; Choe, M.S.; Jang, B.K.; Kim, M.K.; et al. Fyn deficiency attenuates renal fibrosis by inhibition of phospho-Stat3. Kidney Int. 2016, 90, 1285-1297. [CrossRef]

60. Matsui, F.; Babitz, S.A.; Rhee, A.; Hile, K.L.; Zhang, H.; Meldrum, K.K. Mesenchymal stem cells protect against obstruction-induced renal fibrosis by decreasing Stat3 activation and Stat3-dependent MMP-9 production. Am. J. Physiol. Ren. Physiol. 2017, 312, F25-F32. [CrossRef]

61. Leask, A.; Abraham, D.J. TGF- $\beta$ signaling and the fibrotic response. FASEB J. 2004, 18, 816-827. [CrossRef] [PubMed]

62. Chakraborty, D.; Sumova, B.; Mallano, T.; Chen, C.W.; Distler, A.; Bergmann, C.; Ludolph, I.; Horch, R.E.; Gelse, K.; Ramming, A.; et al. Activation of Stat3 integrates common profibrotic pathways to promote fibroblast activation and tissue fibrosis. Nat. Commun. 2017, 8, 1130. [CrossRef] [PubMed]

63. Lee, C.G.; Cho, S.J.; Kang, M.J.; Chapoval, S.P.; Lee, P.J.; Noble, P.W.; Yehualaeshet, T.; Lu, B.; Flavell, R.A.; Milbrandt, J.; et al. Early growth response gene 1-mediated apoptosis is essential for transforming growth factor $\beta 1$-induced pulmonary fibrosis. J. Exp. Med. 2004, 200, 377-389. [CrossRef]

64. Takehara, T.; Tatsumi, T.; Suzuki, T.; Rucker, E.B., 3rd; Hennighausen, L.; Jinushi, M.; Miyagi, T.; Kanazawa, Y.; Hayashi, N. Hepatocyte-specific disruption of Bcl-xL leads to continuous hepatocyte apoptosis and liver fibrotic responses. Gastroenterology 2004, 127, 1189-1197. [CrossRef] [PubMed] 
65. Liu, C.; Tao, Q.; Sun, M.; Wu, J.Z.; Yang, W.; Jian, P.; Peng, J.; Hu, Y.; Liu, C.; Liu, P. Kupffer cells are associated with apoptosis, inflammation and fibrotic effects in hepatic fibrosis in rats. Lab. Investig. 2010, 90, 1805-1816. [CrossRef] [PubMed]

66. Yang, L.; Chan, C.-C.; Kwon, O.-S.; Liu, S.; McGhee, J.; Stimpson, S.A.; Chen, L.Z.; Harrington, W.W.; Symonds, W.T.; Rockey, D.C. Regulation of peroxisome proliferator-activated receptor- $\gamma$ in liver fibrosis. Am. J. Physiol. Gastrointest. Liver Physiol. 2006, 291, G902-G911. [CrossRef] [PubMed]

67. Zhao, M.; Chen, Y.; Ding, G.; Xu, Y.; Bai, M.; Zhang, Y.; Jia, Z.; Huang, S.; Zhang, A. Renal tubular epithelium-targeted peroxisome proliferator-activated receptor- $\gamma$ maintains the epithelial phenotype and antagonizes renal fibrogenesis. Oncotarget 2016, 7, 64690-64701. [CrossRef] [PubMed]

(C) 2019 by the authors. Licensee MDPI, Basel, Switzerland. This article is an open access article distributed under the terms and conditions of the Creative Commons Attribution (CC BY) license (http://creativecommons.org/licenses/by/4.0/). 